\title{
La estrategia de marketing turístico de los Sitios Patrimonio Mundial a través de los eventos 2.0
}

\author{
Concepción Campillo-Alhama*, Alba-María Martínez-Sala** \\ Universidad de Alicante (España)
}

\begin{abstract}
Resumen: La declaración Patrimonio Mundial de la UNESCO, como reconocimiento internacional de los destinos, representa un valor al alza en España. El cambio de paradigma que representa el marketing turístico 2.0 condiciona su gestión estratégica y la desestabilización de la demanda tradicional de los territorios. Los eventos culturales vinculados al patrimonio, difundidos a través de las redes sociales y plataformas multimedia, contribuyen sin duda a reforzar la imagen de marca de dichos destinos ya que son recursos que se identifican como bienes turísticos activos, intencionales y estratégicos. El objetivo de esta investigación es analizar si los eventos 2.0, planificados por las entidades gestoras de destino (DMO) en los perfiles sociales de los Sitios Patrimonio Mundial en España (categoría bienes culturales), representan un factor clave en la dinamización de su promoción turística al integrarse en las estrategias de marketing territorial. Mediante el análisis de contenido, se realiza un estudio exploratorio sobre 578 eventos con perfiles sociales en Facebook y 508 en Twitter que permite verificar la eficacia de la gestión comunicativa y relacional de los eventos 2.0, a partir de tres variables: el análisis de la audiencia (publicaciones y seguimientos), la interacción y el interés suscitado en los nuevos turistas como adprosumers.
\end{abstract}

Palabras Clave: Turismo cultural; Sostenibilidad; Eventos; Patrimonio de la humanidad; Marketing turístico.

\section{Tourism Marketing Strategy of World Heritage Sites through 2.0 events}

Abstract: Becoming a World Heritage Site UNESCO means international recognition and value-added for a tourist destination in any country, above all in terms of online perception. By shifting marketing to social media, however, DMOs upturn the traditional demands placed on the site.. Cultural heritage events promoted via social media undoubtedly help to reinforce the brand of the destinations. Cultural events are active tourism assets with a clear purpose and strategy. The aim of this research is to analyse whether 2.0 promoted events in social media profiles of World Heritage Sites, as planned by the DMO, represent a key factor in the efficient galvanisation of tourism when integrated into territorial marketing strategies. Through content analysis, an exploratory study was carried out on 578 events with social profiles on Facebook and 508 on Twitter that allows us to verify the effectiveness of the communicative and relational 2.0 management of events, from three variables: the analysis of the target audience (publications and follow-ups), the level of interaction, and the interest aroused in the new tourists as adprosumers.

Keywords: Cultural tourism; Sustainability; Events; World heritage; Tourism marketing.

\section{Introducción}

El turismo cultural, vinculado al patrimonio histórico, constituye una actividad fundamental para el desarrollo de las ciudades y sitios que poseen la distinción Patrimonio de la Humanidad por parte de la UNESCO. Esta distinción puede ser una ventaja competitiva respecto a otros núcleos urbanos, si la destination management organization (DMO) del Sitio Patrimonio Mundial (SPM) gestiona de forma sostenible el valor patrimonial de sus bienes culturales para que éstos sean, ante todo, preservados. Por otra parte, las administraciones públicas de los diferentes niveles competenciales, dentro de sus

* Universidad de Alicante; E-mail: concepcion.campillo@ua.es

** Universidad de Alicante: E-mail: albamaria.martinez@ua.es 
planes estratégicos territoriales, son conscientes de la necesidad imperiosa de difundir y dinamizar estos bienes culturales y patrimoniales que representan su propia identidad como territorio; para ello, en sus estrategias de marketing de destino diseñan, ejecutan y evalúan acciones de comunicación y gestión relacional que permiten visibilizar su oferta turística.

Lara de Vicente \& López Guzmán (2004) afirman que las ciudades Patrimonio de la Humanidad son importantes destinos que concentran gran parte de los flujos del turismo cultural en nuestro país. Su identidad, como núcleos urbanos, gira en torno a su patrimonio histórico, cultural y artístico, convirtiéndose en el factor principal de atracción de visitantes que permite explotar las posibilidades turísticas de una determinada área geográfica como destino.

La relevancia de la celebración de eventos turístico-culturales como factor de atracción de visitantes en el contexto de las ciudades y sitios patrimoniales es indiscutible. Tales eventos poseen, en muchas ocasiones, una gran repercusión que tiene como consecuencia directa un aumento notable de visitas; circunstancia que favorece, sin duda, una cierta desestabilización de la demanda turística y, de forma paralela, repercute sobre los niveles de pernoctación en destino.

Dichos eventos vinculados al patrimonio se configuran como proyectos relevantes en la renovación o actualización de la oferta turística, y son capaces de concitar atención e interés por los bienes históricos y culturales; lo que incluso se puede traducir en la repetición de la visita al mismo destino en diversos periodos estacionales. La envergadura del evento, su proyección y notoriedad a través de los medios de comunicación de masas y social media condicionan tanto el perfil del visitante como su comportamiento turístico (Troitiño, 2003; Domínguez \& Araujo, 2012).

La organización de eventos, como actividad estratégica y experiencial, constituye un elemento sustancial en el posicionamiento de cualquier territorio (Jiménez Morales \& de San Eugenio Vela, 2009a, 2009b; Campillo, 2012) que permite, además de su promocomercialización (Ejarque, 2016; González, 2016), servir como catalizador de imágenes para su posicionamiento. El destino se convierte así en algo más que un simple espacio físico: se convierte en un símbolo identitario como resultado de la proyección cultural del evento a través de la actividad turística (Campillo, 2012).

En el actual contexto de la sociedad digital, el paradigma de la comunicación entre la DMO y el turista potencial ha cambiado sustancialmente: desde los planteamientos clásicos y tradicionales unidireccionales de hace más de una década, a través de los medios de comunicación de masas, se ha producido una evolución hacia el nuevo perfil del usuario en medios sociales, basada en la filosofía 2.0 y una interacción bidireccional permanente. Este cambio de paradigma ha transformado no sólo la estrategia de comunicación conducente a reforzar las marcas turísticas Patrimonio de la Humanidad, sino también la relación del destino turístico con el visitante potencial a partir de los eventos 2.0, que se benefician de los medios sociales tanto en su organización, como en su ejecución y difusión.

A través de las redes sociales y otras plataformas multimedia se establece un proceso de comunicación bidireccional y de gestión relacional entre los usuarios del producto turístico y los gestores de la DMO (Martínez-Sala, Monserrat-Gauchi \& Campillo-Alhama, 2017) que resulta clave para cristalizar, a medio y largo plazo, la reputación territorial de la marca turística. Y los eventos, en este sentido, pueden ser utilizados como verdaderos recursos turísticos activos, claramente intencionales y estratégicos.

\section{Turismo cultural, patrimonio histórico y sostenibilidad}

A partir de 1990, superado el tradicional turismo de masas desarrollado durante los años 60 y 80 en España (Santana, 2003, 2008; Ejarque, 2016), la actividad turística aparece con fuerza en la política municipal a través de áreas de gestión centralizadas o descentralizadas, y se diseñan planes estratégicos a partir de líneas clave orientadas a desarrollar, entre otras, las potencialidades turísticas de los territorios. No obstante, tal y como apuntan Troitiño Vinuesa \& Troitiño Torralba (2012:150) habrá que esperar hasta finales del S.XX para identificar verdaderas estrategias de desarrollo territorial vinculadas a la actividad turística cultural y patrimonial.

Lara de Vicente \& López Guzmán (2004: 245) afirman que "el turismo cultural se justifica por la necesidad cada vez mayor que tienen las personas de conocer, comprender y valorar el patrimonio que nos han legado nuestros antepasados". Y añaden que, frente al turismo cultural masivo es imprescindible establecer mecanismos pertinentes que velen por la integridad de los valores patrimoniales, evitando así que cualquier bien cultural se convierta de forma indiscriminada en un producto comercial-turístico. En este sentido, Laguna (2005), Martos (2013) y Ruiz \& Pulido (2015) inciden en que la explotación turística de los bienes patrimoniales conlleva una serie de riesgos básicos de primer nivel vinculados a la 
degradación del patrimonio y de los valores culturales si no se evita una concentración espacio-temporal desmedida de los turistas en determinados destinos.

La mayoría de acciones orientadas al ámbito turístico cultural se basan, siguiendo a Santana (2008: 275), "en el sostenimiento, estéticamente correcto, de los entornos no alterados, los estilos de vida tradicionales, las identidades manifiestas a través de las prácticas cotidianas y en entornos equilibrados". Desde esta óptica, los territorios ofertan a sus visitantes experiencias únicas y relevantes, muchas de ellas basadas en eventos locales autóctonos a través de los cuáles es posible obtener una vinculación emocional positiva hacia el territorio, con efectos muy duraderos.

Y en este sentido, Pulido \& López (2013) se refieren al concepto del turismo sostenible para llegar a diversas conclusiones: en primera instancia, consideran que la cuestión del cambio de modelo turístico en España, para que éste sea mucho más sostenible, no se ha planteado nunca con profundidad, ya que la mayoría de los intentos han sido análisis de caso específicos y aislados que no permiten analizar el problema en toda su dimensión e integridad. Añaden, además, que es imprescindible que dicha política estratégica se planifique desde una perspectiva normativa e institucional, e insisten en la necesidad de introducir modelos eficientes de gobernanza en los que los grupos de interés se involucren en la gestión de los destinos, provocando espacios de consenso y entornos colaborativos en la esfera pública y privada. La gobernanza entre el sector público y privado, tal y como apunta Ejarque (2016), es consecuencia directa de las características de un turismo que es transversal, y que necesita de la actuación coordinada de todos los agentes económicos, actores políticos e institucionales para la promoción y comercialización del destino.

Coincidimos con Pulido \& López (2013) cuando insisten en la conveniencia de elevar la sostenibilidad a una categoría superior a la conciencia social y medioambiental, en tanto que valor añadido que puede resultar clave en la promoción de los territorios como oferta turística. No es sólo, por tanto, una cuestión de preservación de los bienes naturales y patrimoniales, sino de conseguir además un posicionamiento turístico diferenciador que contribuya a la generación de importantes incentivos y recursos económicos.

La consecuencia directa de esta necesidad manifiesta para preservar los bienes materiales culturales es la reacción de diferentes organizaciones gubernamentales, intergubernamentales, nacionales, internacionales o supranacionales como la UNESCO, cuando crea la distinción Patrimonio Cultural de la Humanidad y establece la Convención para la Protección del Patrimonio Mundial Cultural y Natural (1972).

A fecha de enero de 2017, se encuentran inscritos en la lista de Patrimonio Mundial de la UNESCO un total de 1.052 bienes materiales (814 culturales, 203 naturales y 35 mixtos). Sin duda, poseer dicha distinción conlleva un alto prestigio que puede potenciar flujos turísticos e impactos positivos en el territorio; siendo éste, junto con la preservación de los bienes, uno de los principales motivos que inspiraron la creación de dicha Convención, como se puede constatar en el preámbulo de su articulado (UNESCO, 2004).

Este reconocimiento también posee un coste asociado, ya que los visitantes pueden llegar a generar una serie de conflictos y tensiones con su actividad turística, tal y como ya fue advertido durante la década de los años 80 (Pulido \& López, 2013). En este sentido, los beneficios del turismo no están siempre garantizados, tal y como afirman Wang \& Zan (2011), Martos (2013) o Ruiz \& Pulido (2015); entre otras razones, por la idiosincrasia particular de cada territorio al mostrar realidades de muy diferente naturaleza, su identificación como destinos consolidados turísticamente o como destinos emergentes.

Las ciudades históricas, como destinos turísticos, se caracterizan por una serie de factores que pueden ser positivos o negativos (Velasco, 2009; Martos, 2013; Márquez-González \& Caro-Herrero, 2017), y que De la Calle (2002) identifica atendiendo a su patrimonio, la demanda existente, la selectividad y la simplificación de los bienes ofertados, la heterogeneidad de la actividad turística y la amplitud de los efectos conseguidos: el patrimonio ${ }^{1}$ constituye así el epicentro de la identidad territorial de las ciudades históricas y, en consecuencia, representa su mayor valor.

La conservación y adecuación de los bienes culturales patrimoniales necesita de una importante y constante financiación a través de recursos económicos propios (como las subvenciones) y ajenos. Por tanto, resulta preciso obtener recursos económicos que proceden del sector turístico (Lara de Vicente \& López-Guzmán, 2004): entre ellos, la celebración de eventos culturales.

\section{Ciudades históricas y marca territorio Sitio Patrimonio Mundial (SPM)}

Desde la perspectiva turística, podemos considerar que la mayor rentabilidad para las ciudades históricas se produce cuando la visita obedece a un interés claro por su cultura, naturaleza y patrimonio; lo que permite consolidar a estos destinos SPM como potentes marcas estratégicas territoriales y 
focos permanentes de turismo cultural (Okech, 2010), ya que además de experimentar un aumento considerable de flujos turísticos, permiten fidelizar la experiencia de visita al destino. Y así, podemos observar cómo la marca SPM, en ocasiones, se utiliza para potenciar otros elementos o acontecimientos como festivales, muestras, exposiciones, espectáculos o macro-eventos, a través de los cuáles, y de forma sinérgica, se refuerza a sí misma (Campillo, 2012).

En nuestro país, las ciudades patrimoniales son un valor al alza, según informes de Turespaña (2007), del World Tourism Organization (UNWTO) (2015, 2016) y del Grupo Ciudades Patrimonio de la Humanidad de España (2015). Y desde la perspectiva de la demanda, podemos afirmar que este tipo de destinos tiene, a nivel mundial, una demanda notable y creciente.

En la siguiente tabla se reflejan los 40 Sitios Patrimonio Mundial en España que representan la delimitación de nuestra investigación, sus bienes culturales y la organización gestora de cada uno de los destinos turísticos.

\section{Tabla 1: Sitios Patrimonio Mundial (SPM) de carácter cultural² (España)}

\begin{tabular}{|c|c|c|c|c|c|}
\hline & \multicolumn{2}{|c|}{ Localización } & \multirow{2}{*}{\begin{tabular}{|l|}
\multicolumn{1}{|c|}{ Bienes } \\
patrimonio mundial \\
Centro Histórico de \\
Córdoba
\end{tabular}} & \multirow{2}{*}{\begin{tabular}{|c|}
$\begin{array}{c}\text { Año } \\
\text { inscripción }\end{array}$ \\
1984,1994 \\
\end{tabular}} & \multirow{2}{*}{\begin{tabular}{|c|} 
Web dmo \\
http://www.turismodecordoba.org/
\end{tabular}} \\
\hline 1 & Municipio & Córdoba & & & \\
\hline 2 & Municipio & Granada & $\begin{array}{l}\text { Alhambra, Generalife y } \\
\text { Albaicín de Granada }\end{array}$ & 1984,1994 & http://www.granadatur.com/ \\
\hline 3 & Municipio & $\begin{array}{l}\text { Barcelona y } \\
\text { Santa Coloma de } \\
\text { Cervelló } \\
\end{array}$ & Obra de Gaudí & 1984,2005 & http://www.barcelonaturisme.com/ \\
\hline 4 & Municipio & Burgos & Catedral de Burgos & 1984 & http://www.turismoburgos.org/ \\
\hline 5 & Municipio & $\begin{array}{l}\text { San Lorenzo de el } \\
\text { Escorial }\end{array}$ & $\begin{array}{l}\text { Monasterio y Real Sitio } \\
\text { de El Escorial }\end{array}$ & 1984 & http://www.sanlorenzoturismo.es/ \\
\hline 6 & $\begin{array}{l}\text { Comunidad } \\
\text { autónoma }\end{array}$ & $\begin{array}{l}\text { Asturias } \\
\text { (municipios: } \\
\text { Oviedo y Lena) } \\
\end{array}$ & $\begin{array}{l}\text { Monumentos de Oviedo y } \\
\text { del reino de Asturias }\end{array}$ & 1985,1998 & https://www.turismoasturias.es/ \\
\hline 7 & $\begin{array}{l}\text { Comunidad } \\
\text { autónoma }\end{array}$ & $\begin{array}{l}\text { Cantabria, } \\
\text { País Vasco y } \\
\text { Principado de } \\
\text { Asturias }\end{array}$ & $\begin{array}{l}\text { Cueva de Altamira y Arte } \\
\text { Rupestre Paleolítico de la } \\
\text { Cornisa Cantábrica }\end{array}$ & 1985,2008 & https://www.turismodecantabria.com/ \\
\hline 8 & Municipio & Ávila & $\begin{array}{l}\text { Ciudad Vieja de Ávila e } \\
\text { iglesias extramuros }\end{array}$ & 1985,2007 & http://www.avilaturismo.com/ \\
\hline 9 & Municipio & Segovia & $\begin{array}{l}\text { Ciudad Vieja de Segovia y } \\
\text { su Acueducto }\end{array}$ & 1985 & http://www.turismodesegovia.com/ \\
\hline 10 & Municipio & $\begin{array}{l}\text { Santiago de } \\
\text { Compostela }\end{array}$ & $\begin{array}{l}\text { Ciudad Vieja de Santiago } \\
\text { de Compostela }\end{array}$ & 1985 & http://www.santiagoturismo.com/ \\
\hline 11 & $\begin{array}{l}\text { Comunidad } \\
\text { autónoma }\end{array}$ & Aragón & $\begin{array}{l}\text { Arquitectura mudéjar de } \\
\text { Aragón }\end{array}$ & 1986,2001 & http://www.turismodearagon.com/ \\
\hline 12 & Municipio & Toledo & $\begin{array}{l}\text { Ciudad Histórica de } \\
\text { Toledo }\end{array}$ & 1986 & http://www.toledo-turismo.com/ \\
\hline 13 & Municipio & Cáceres & Ciudad Vieja de Cáceres & 1986 & http://turismo.ayto-caceres.es/ \\
\hline 14 & Municipio & Sevilla & $\begin{array}{l}\text { Catedral, Alcázar y } \\
\text { Archivo de Indias de } \\
\text { Sevilla }\end{array}$ & 1987 & http://www.visitasevilla.es/ \\
\hline 15 & Municipio & Salamanca & $\begin{array}{l}\text { Ciudad Vieja de } \\
\text { Salamanca }\end{array}$ & 1988 & http://www.salamanca.es \\
\hline 16 & Municipio & $\begin{array}{l}\text { Vimbodí (comarca } \\
\text { Cuenca de } \\
\text { Barberá) }\end{array}$ & Monasterio de Poblet & 1991 & http://www.concadebarbera.info/ \\
\hline 17 & $\begin{array}{l}\text { Comunidad } \\
\text { autónoma }\end{array}$ & $\begin{array}{l}\text { Galicia, Navarra, } \\
\text { Aragón, La Rioja } \\
\text { y Castilla y León }\end{array}$ & El Camino de Santiago & 1993 & http://www.santiagoturismo.com/ \\
\hline
\end{tabular}




\begin{tabular}{|c|c|c|c|c|c|}
\hline 18 & Municipio & Guadalupe & $\begin{array}{l}\text { Monasterio Real de Santa } \\
\text { María de Guadalupe }\end{array}$ & 1993 & - \\
\hline 19 & Municipio & Mérida & $\begin{array}{l}\text { Conjunto arqueológico de } \\
\text { Mérida }\end{array}$ & 1993 & http://www.turismomerida.org/ \\
\hline 20 & Municipio & Cuenca & $\begin{array}{l}\text { Ciudad Histórica } \\
\text { amurallada de Cuenca }\end{array}$ & 1996 & http://turismo.cuenca.es/ \\
\hline 21 & Municipio & Valencia & $\begin{array}{l}\text { La Lonja de la Seda de } \\
\text { Valencia }\end{array}$ & 1996 & http://www.visitvalencia.com/ \\
\hline 22 & Provincia & $\begin{array}{l}\text { León (comarca El } \\
\text { Bierzo) }\end{array}$ & Las Médulas & 1997 & http://turismodelbierzo.es/ \\
\hline 23 & Municipio & Barcelona & $\begin{array}{l}\text { Palau de la Música } \\
\text { Catalana y Hospital de } \\
\text { Sant Pau }\end{array}$ & 1997,2008 & http://www.barcelonaturisme.com/ \\
\hline 24 & Municipio & $\begin{array}{l}\text { San Millán de la } \\
\text { Cogolla (valle de } \\
\text { San Millán) }\end{array}$ & $\begin{array}{l}\text { Monasterios de San } \\
\text { Millán de Yuso y de Suso }\end{array}$ & 1997 & - \\
\hline 25 & Provincia & Salamanca & $\begin{array}{l}\text { Yacimientos de Arte } \\
\text { Rupestre Prehistórico } \\
\text { del Valle del Côa y Siega } \\
\text { Verde }\end{array}$ & 1998,2010 & http://www.salamancaemocion.es/ \\
\hline 26 & Municipio & Alcalá de Henares & $\begin{array}{l}\text { Universidad y recinto } \\
\text { histórico de Alcalá de } \\
\text { Henares }\end{array}$ & 1998 & http://www.turismoalcala.es/ \\
\hline 27 & $\begin{array}{l}\text { Comunidad } \\
\text { autónoma }\end{array}$ & $\begin{array}{l}\text { Cataluña, } \\
\text { Andalucía, } \\
\text { Murcia, } \\
\text { Comunidad } \\
\text { Valenciana, } \\
\text { Aragón y Castilla- } \\
\text {-La Mancha } \\
\end{array}$ & $\begin{array}{l}\text { Arte rupestre del Arco } \\
\text { Mediterráneo de la } \\
\text { Península Ibérica }\end{array}$ & 1998 & - \\
\hline 28 & Municipio & $\begin{array}{l}\text { San Cristóbal de } \\
\text { La Laguna }\end{array}$ & $\begin{array}{l}\text { San Cristóbal de La } \\
\text { Laguna }\end{array}$ & 1999 & http://www.turismolalaguna.org/ \\
\hline 29 & Municipio & $\begin{array}{l}\text { Atapuerca e Ibeas } \\
\text { de Juarros }\end{array}$ & $\begin{array}{l}\text { Cuenca arqueológica de } \\
\text { Atapuerca }\end{array}$ & 2000 & - \\
\hline 30 & Municipio & Tarragona & $\begin{array}{l}\text { Conjunto arqueológico de } \\
\text { Tárraco }\end{array}$ & 2000 & http://www.tarragonaturisme.cat/ \\
\hline 31 & Comarca & $\begin{array}{l}\text { Alta Ribagorça } \\
\text { (Valle de Boí) }\end{array}$ & $\begin{array}{l}\text { Iglesias románicas } \\
\text { catalanas del Vall de Boí }\end{array}$ & 2000 & http://www.vallboi.cat/ \\
\hline 32 & Municipio & Elche & Palmeral de Elche & 2000 & http://www.visitelche.com/ \\
\hline 33 & Municipio & Lugo & Muralla romana de Lugo & 2000 & http://lugo.gal/es/lugo-destino-turistico-0 \\
\hline 34 & Municipio & Aranjuez & $\begin{array}{l}\text { Paisaje cultural de } \\
\text { Aranjuez }\end{array}$ & 2001 & - \\
\hline 35 & Municipio & Úbeda y Baeza & $\begin{array}{l}\text { Conjuntos monumentales } \\
\text { renacentistas de Úbeda } \\
\text { y Baeza }\end{array}$ & 2003 & http://ubedaybaezaturismo.com/ \\
\hline 36 & Municipio & $\begin{array}{l}\text { Portugalete y } \\
\text { Getxo }\end{array}$ & El Puente de Vizcaya & 2006 & http://www.mybilbaobizkaia.eus/ \\
\hline 37 & Municipio & A Coruña & Torre de Hércules & 2009 & http://www.turismocoruna.com/ \\
\hline 38 & Isla & Mallorca & $\begin{array}{l}\text { Paisaje cultural de la } \\
\text { Sierra de la Tramontana }\end{array}$ & 2011 & http://www.infomallorca.net/ \\
\hline 39 & Municipio & Almadén & $\begin{array}{l}\text { Patrimonio del Mercurio: } \\
\text { Almadén e Idrija }\end{array}$ & 2012 & http://www.almaden.es/turismo.html \\
\hline 40 & Municipio & Antequera & Dólmenes de Antequera & 2016 & http://turismo.antequera.es/ \\
\hline
\end{tabular}

Fuente: Área de Patrimonio Cultural del Ministerio de Educación, Cultura y Deporte (2017), Organización de las Naciones Unidas para la Educación la Ciencia y la Cultura (UNESCO, 2016). Elaboración propia 
Esta apuesta por parte de los territorios en la gestión estratégica de la marca SPM (con mayor o menor intensidad) es una muestra clara de cómo es posible desestabilizar la demanda tradicional (Troitiño, 2000; Laguna, 2005; Martos, 2013) que, en España, se sigue asociando con el turismo de sol y playa (Martínez-Sala, 2015). No obstante, insistimos en que a pesar de la importante repercusión económica que pueden conseguir estos destinos, a partir de la inversión tanto pública como privada (Pérez, 2006; Martos 2013), la gestión del desarrollo territorial y urbanístico de los SPM debe acometerse siempre desde la perspectiva de la sostenibilidad socialmente responsable para evitar, siguiendo a Martos (2013:61-63), fenómenos tan desfavorables y contraproducentes como la musealización ${ }^{3}$, la banalización del patrimonio cultural, el monocultivo turístico, la congestión y concentración de visitas turísticas, los efectos económicos negativos, la gentrificación ${ }^{4}$ o la decepción y malestar de la población residente.

Desde la última década, se ha producido en la actividad turística un cambio radical que obedece a las nuevas características del mercado y a los canales de información de los que dispone el turista, a través de los cuáles se aproxima al destino sin contar con los operadores como agentes necesarios en el proceso de intercambio. Esta circunstancia hace que la DMO, si quiere seguir manteniendo su capacidad e influencia para intervenir en ese proceso de intermediación entre el turista potencial y el destino, deba replantearse, tal y como afirman autores como Ejarque (2016) o González (2016), el tradicional modelo de promoción institucional, para pasar a otro de promocomercialización que se ajuste a las nuevas características del usuario turístico y que represente a un sistema integrado configurado por agentes económicos, políticos, sociales y culturales.

\section{El nuevo paradigma del marketing turístico 2.0}

El marketing de destinos turísticos es la disciplina que permite vincular al destino con el mercado (Bigné, Font \& Andreu, 2000). Representa un proceso secuencial y recurrente en el que la DMO "planifica, investiga, controla y monitoriza los resultados de las actividades que desarrolla para identificar y conectar las necesidades de los potenciales turistas con los objetivos generales del destino", tal y como apunta Ejarque (2016: 125).

Cuando se produjo la irrupción de Internet (a finales de los 90), los modelos de información turística y de prestación de servicios de tipo presencial (oficinas y puntos de información) convivían con los digitales. La llegada de la web 2.0 facilitó que la información turística no sólo fuera diseñada y producida por la DMO o por las empresas vinculadas al sector, sino por los turistas que ya habían tenido contacto con el destino y que colaboraban en la elaboración de contenidos, mostrando sus opiniones y sensaciones (Sigala, 2009; Xiang \& Gretzel, 2010; Caro, Luque \& Zayas, 2015; Huertas-Roig, Setió Pamies \& Míguez-González, 2015; Marine-Roig \& Clavé, 2015; Martínez-Sala, Monserrat-Gauchi \& Campillo-Alhama, 2017; Yang, X., 2017).

Los nuevos medios sociales han convertido al turista actual en un adprosumer porque anuncia o promociona el destino ( $a d$ ), produce informaciones sobre él (pro) y es consumidor del producto o subproductos turísticos (sumer) (Caro, Luque \& Zayas, 2015). No actúa como mero espectador, sino que participa de forma activa en dicha experiencia, la comparte e influye en otros turistas potenciales con sus opiniones, poniendo en valor el destino (Huertas-Roig, 2008; Pantano, Servidio \& Viassone, 2011; Hays, Page \& Buhalis, 2013). Se convierte, por tanto, en un verdadero influenciador frente a los agentes tradicionales (agencias de viaje, touroperadores y medios de comunicación). Este nuevo paradigma de un consumidor proactivo, durante todo el proceso, representa la clave fundamental de la gestión reputacional de los destinos (Marine-Roig \& Clavé, 2015; Márquez-González \& Caro-Herrero, 2017).

El marketing turístico 2.0 se centra en la filosofía del inbound (como marketing de permiso o marketing de entrada) para generar interés y atraer visitas a la web institucional gestionada por la DMO. En consecuencia, podemos identificar el marketing de entrada como una estrategia orientada al consumidor: lo que significa que se centra en los clientes y clientes potenciales más que en un producto turístico concreto o en el propio destino. Desde la perspectiva turística, representa "la estrategia de marketing que utiliza los contenidos, los motores de búsqueda y las redes sociales para atraer a los usuarios" (Ejarque, 2016: 455).

Incidiendo en la definición de dicho autor, en primer término, la estrategia de contenidos permite diseñar y dirigir a los potenciales clientes contenidos específicos, ya que los social media favorecen una alta segmentación de los grupos de interés. A través de los medios sociales podemos crear contenidos de calidad, capaces de transmitir valores y emociones que provoquen una reacción positiva en el destinatario para que dicho contenido sea compartido. 
Por otra parte, debemos hacer referencia a la optimización de los motores de búsqueda o search engine optimization (SEO), ya que para cualquier destino turístico es fundamental ser visible y localizable de forma rápida a través de internet. La SEO permite catalogar de forma óptima el sitio web del destino y generar tráfico gratuito procedente de los motores de búsqueda, consiguiendo así un posicionamiento natural. El marketing de los motores de búsqueda o search engine marketing (SEM) permite implementar actividades de marketing digital orientadas a incrementar la visibilidad y el rastro de un sitio web por los motores de búsqueda con el objetivo principal de reforzar la promoción online.

En tercer término, la filosofía inbound se basa en un plan de marketing para las redes sociales que permite, junto con las variables anteriores, incrementar la notoriedad y la visibilidad del destino, así como complementar la estrategia de marketing. Por una parte, la comunicación directa y en tiempo real que conllevan las redes sociales obliga a la DMO, en numerosas ocasiones, y en función de las reacciones de los usuarios, a cambiar el contenido, tono o estilo de los mensajes y su enfoque relacional. Por otra, la información no oficial, como las opiniones de los visitantes, influencers o bloggers puede ser un recurso muy interesante dentro de la estrategia digital y de redes sociales de la DMO, al producir contenidos de calidad y de alto interés, actualizar constantemente el sitio web del destino y añadir contenidos a sus aplicaciones móviles que se diseñan como herramienta de difusión del destino turístico, tal y como apuntan Romero-Rodríguez, Torres-Toukoumidis \& Aguaded (2016).

\section{Los eventos 2.0 en la estrategia de marketing de destino}

El destino es un conjunto de recursos materiales, servicios y experiencias culturales, formativas, gastronómicas, de ocio y tiempo libre que se interrelacionan y que constituyen su oferta global como producto turístico. Los eventos, en este sentido, se identifican como verdaderos recursos que sirven para reforzar el valor propio de los destinos. La gestión de eventos o acontecimientos programados de gran relevancia constituye, sin duda, un desafío y una oportunidad de gran valor para consolidar la oferta cultural, tradicional e identitaria; se erigen, en consecuencia, como elementos indispensables en el marketing integrado (offline y online) de cualquier destino turístico. Y, en consecuencia, el diseño y la gestión eficiente de los eventos actúa como un factor clave en la consolidación de la marca territorio (Laguna, 2005; Jiménez \& San Eugenio, 2009b; Campillo, 2012; Martos, 2013; Folgado, 2014; Huertas-Roig, 2014; Fernández, López \& Arévalo, 2016; Marine-Roig, Martin-Fuentes \& Daries-Ramon, 2017).

El nuevo paradigma que representa el marketing turístico 2.0 también ha repercutido en el sector de los eventos vinculados al marketing de destino para los Sitios Patrimonio Mundial. El evento 2.0 es aquel que se beneficia del uso de los medios sociales tanto en su organización, como en su realización y comunicación; de entre todos ellos, destacan las redes sociales porque proporcionan nuevas oportunidades para organizar, difundir y comunicar el evento turístico, lograr mucha más notoriedad, vinculación y afluencia de participantes, tanto físicos como virtuales.

A través del uso de los medios sociales, la DMO puede generar antes del evento una comunidad, aportando contenidos relacionados (entrevistas, actualidad e información turística sobre el destino) o contactando con líderes de opinión, bloggers e influencers. Y, en este sentido, la investigación llevada a cabo por el Event Marketing Institute y la compañía FreemanXP (2015) concluye que Facebook y Twitter se configuran como las mejores redes sociales para la difusión y promoción de un evento.

Facebook se considera la plataforma más efectiva antes y después del evento, mientras que Twitter se ha convertido en la más popular durante el desarrollo del evento y su retransmisión. Así lo constatan informes como el Social Media and Events Report (2014), al reflejar que la mayoría de los tweets relacionados con un evento se producen durante su celebración (60\%); surge un segundo pico unos días después del evento, debido a la publicación de material que los usuarios comparten (y que representa el 35\%). Además, el uso de etiquetas propias en Twitter y su combinación con otras ya consolidadas en esta plataforma permite fomentar la difusión del evento en redes sociales (Campillo, Ramos \& Castelló, 2014).

Durante el evento, los medios sociales pueden fomentar la creación de una red de contactos, la conversación entre los asistentes y organizadores del evento, la interacción entre los asistentes y participantes o la compartición de material (videos, imágenes o noticias). Tras el evento, la entidad organizadora podrá recibir la retroalimentación de los asistentes a través de encuestas, monitorizar su presencia en plataformas 2.0 (a través de comentarios o menciones que sirvan para realizar una evaluación rigurosa del mismo) y mantener la comunidad creada, en el caso de eventos que se repiten periódicamente. 
La utilización eficiente de plataformas colaborativas para la organización de los eventos, junto con los medios sociales, favorecerá su gestión automatizada, una promoción eficiente, mayor participación social y la generación de valor hacia el destino. En consecuencia, resulta imprescindible establecer una estrategia previa bien definida, que integre los medios sociales y digitales con el resto de canales de comunicación offline que se van a utilizar en la difusión del evento turístico.

\section{Objetivos y metodología}

El objetivo de esta investigación es analizar si los eventos 2.0 que se integran en la estrategia de marketing de los 40 Sitios Patrimonio Mundial en España (categoría bienes culturales) resultan eficaces en la dinamización de la actividad turística, a partir de su difusión en los perfiles de redes sociales de las entidades gestoras del destino. Para ello se han analizado, durante el periodo de un año (desde el 1 de noviembre de 2015 al 31 de octubre de 2016), todas aquellas publicaciones sobre eventos desarrollados por parte de las DMO, que se han vinculados al patrimonio histórico y cultural de los municipios, comunidades autónomas o comarcas reconocidas por la UNESCO con la distinción Sitio Patrimonio Mundial: 578 eventos en Facebook y 508 en Twitter representan la delimitación de nuestro contexto de investigación. Mediante el análisis de contenido (Batthyány \& Cabrera 2011), se realiza un estudio exploratorio que nos permite verificar el nivel de eficacia de la gestión comunicativa y relacional de los eventos 2.0 en la estrategia integrada de marketing turístico de dichos destinos.

Tabla 2: Perfiles en redes sociales

\begin{tabular}{|c|c|c|c|}
\hline & $\begin{array}{c}\text { Bienes } \\
\text { Patrimonio Mundial } \\
\text { Cultural }\end{array}$ & Perfil Facebook & Perfil Twitter \\
\hline 1 & $\begin{array}{l}\text { Centro Histórico de } \\
\text { Córdoba }\end{array}$ & $\begin{array}{l}\text { https://www.facebook.com/ } \\
\text { TurismoCordobaESP }\end{array}$ & https://twitter.com/CordobaESP \\
\hline 2 & $\begin{array}{l}\text { Alhambra, Generalife y } \\
\text { Albaicín de Granada }\end{array}$ & https://www.facebook.com/granadaturismo & https://twitter.com/granadaturismo \\
\hline 3 & Obra de Gaudí & https://www.facebook.com/visitbarcelona & https://twitter.com/VisitBCN_ES \\
\hline 4 & Catedral de Burgos & https://www.facebook.com/DestinoBurgos/ & https://twitter.com/BurgosTur \\
\hline 5 & $\begin{array}{l}\text { Monasterio y Real Sitio } \\
\text { de El Escorial }\end{array}$ & $\begin{array}{l}\text { https://www.facebook.com/ } \\
\text { turismosanlorenzoescorial }\end{array}$ & https://twitter.com/SLorenzoTurismo \\
\hline 6 & $\begin{array}{l}\text { Monumentos de Oviedo y } \\
\text { del reino de Asturias }\end{array}$ & https://www.facebook.com/TurismoAsturias & https://twitter.com/TurismoAsturias \\
\hline 7 & $\begin{array}{l}\text { Cueva de Altamira y } \\
\text { Arte Rupestre Paleolítico } \\
\text { de la Cornisa Cantábrica }\end{array}$ & https://www.facebook.com/cantabriaturismo/ & https://twitter.com/cant_infinita \\
\hline 8 & $\begin{array}{l}\text { Ciudad Vieja de Ávila e } \\
\text { iglesias extramuros }\end{array}$ & https://www.facebook.com/AvilaTurismo.oficial & https://twitter.com/Avila_Turismo \\
\hline 9 & $\begin{array}{l}\text { Ciudad Vieja de Segovia } \\
\text { y su Acueducto }\end{array}$ & https://www.facebook.com/TurismodeSegovia & https://twitter.com/Avila_Turismo \\
\hline 10 & $\begin{array}{l}\text { Ciudad Vieja de Santiago } \\
\text { de Compostela }\end{array}$ & https://www.facebook.com/TurismodeSantiago & https://twitter.com/Avila_Turismo \\
\hline 11 & $\begin{array}{l}\text { Arquitectura mudéjar de } \\
\text { Aragón }\end{array}$ & https://www.facebook.com/TurismodeAragon/ & https://twitter.com/Avila_Turismo \\
\hline 12 & $\begin{array}{l}\text { Ciudad Histórica de } \\
\text { Toledo }\end{array}$ & https://www.facebook.com/toledoturismo & https://twitter.com/Avila_Turismo \\
\hline 13 & Ciudad Vieja de Cáceres & https://www.facebook.com/turismocc/ & - \\
\hline 14 & $\begin{array}{l}\text { Catedral, Alcázar y } \\
\text { Archivo de Indias de } \\
\text { Sevilla }\end{array}$ & https://www.facebook.com/Sevilla & https://twitter.com/sevillaciudad \\
\hline
\end{tabular}




\begin{tabular}{|c|c|c|c|}
\hline 15 & $\begin{array}{l}\text { Ciudad Vieja de } \\
\text { Salamanca }\end{array}$ & https://www.facebook.com/TurismoSalamanca/ & - \\
\hline 16 & Monasterio de Poblet & https://www.facebook.com/enoturismeconca & https://twitter.com/concaturisme \\
\hline 17 & El Camino de Santiago & https://www.facebook.com/CaminoXacobeo & https://twitter.com/camino_xacobeo \\
\hline 18 & $\begin{array}{l}\text { Monasterio Real } \\
\text { de Santa María de } \\
\text { Guadalupe }\end{array}$ & $\begin{array}{l}\text { https://www.facebook.com/ } \\
\text { OficinaTurismoGuadalupe/ }\end{array}$ & $\begin{array}{l}\text { https://twitter.com/OTGuadalupe?ref } \\
\text { src=twsrc\%5Etfw }\end{array}$ \\
\hline 19 & $\begin{array}{l}\text { Conjunto arqueológico de } \\
\text { Mérida }\end{array}$ & https://www.facebook.com/turmerida/ & - \\
\hline 20 & $\begin{array}{l}\text { Ciudad Histórica } \\
\text { amurallada de Cuenca }\end{array}$ & $\begin{array}{l}\text { https://www.facebook.com/ } \\
\text { TurismoAyuntamientodeCuenca }\end{array}$ & https://twitter.com/Turismo_Cuenca \\
\hline 21 & $\begin{array}{l}\text { La Lonja de la Seda de } \\
\text { Valencia }\end{array}$ & https://www.facebook.com/turismovalencia & https://twitter.com/Valenciaturismo \\
\hline 22 & Las Médulas & https://www.facebook.com/turismobierzo & https://twitter.com/turismobierzo \\
\hline 23 & $\begin{array}{l}\text { Palau de la Música } \\
\text { Catalana y Hospital de } \\
\text { Sant Pau }\end{array}$ & https://www.facebook.com/visitbarcelona & https://twitter.com/VisitBCN_ES \\
\hline 24 & $\begin{array}{l}\text { Monasterios de San } \\
\text { Millán de Yuso y de Suso }\end{array}$ & - & - \\
\hline 25 & $\begin{array}{l}\text { Universidad y recinto } \\
\text { histórico de Alcalá de } \\
\text { Henares }\end{array}$ & - & https://twitter.com/ahturismo \\
\hline 26 & $\begin{array}{l}\text { Arte rupestre del Arco } \\
\text { Mediterráneo de la } \\
\text { Península Ibérica }\end{array}$ & - & - \\
\hline 27 & $\begin{array}{l}\text { San Cristóbal de La } \\
\text { Laguna }\end{array}$ & https://www.facebook.com/TurismoLaLaguna & https://twitter.com/turismo_ll \\
\hline 28 & $\begin{array}{l}\text { Cuenca arqueológica de } \\
\text { Atapuerca }\end{array}$ & - & - \\
\hline 29 & $\begin{array}{l}\text { Conjunto arqueológico de } \\
\text { Tárraco }\end{array}$ & https://www.facebook.com/TarragonaTurismo & https://twitter.com/tgnturisme \\
\hline 30 & $\begin{array}{l}\text { Iglesias románicas } \\
\text { catalanas del Vall de Boí }\end{array}$ & https://www.facebook.com/ValldeBoi & https://twitter.com/ValldeBoi \\
\hline 31 & Palmeral de Elche & https://www.facebook.com/visitelche & https://twitter.com/visitelche \\
\hline 32 & Muralla romana de Lugo & https://www.facebook.com/LugoTurismo/about/ & https://twitter.com/LugoTurismo \\
\hline 33 & $\begin{array}{l}\text { Paisaje cultural de } \\
\text { Aranjuez }\end{array}$ & - & - \\
\hline 34 & $\begin{array}{l}\text { Conjunto monumental } \\
\text { renacentista de Úbeda } \\
\text { y Baeza }\end{array}$ & $\begin{array}{l}\text { https://www.facebook.com/ } \\
\text { ubedaybaezaturismo/ }\end{array}$ & https://twitter.com/ubedabaezaturis \\
\hline 35 & El Puente de Vizcaya & https://www.facebook.com/mybilbaoBizkaia & https://twitter.com/mybilbaobizkaia \\
\hline 36 & Torre de Hércules & https://www.facebook.com/turismocoruna & https://twitter.com/CorunaTurismo \\
\hline 37 & $\begin{array}{l}\text { Yacimientos de Arte } \\
\text { Rupestre Prehistórico } \\
\text { del Valle del Côa y Siega } \\
\text { Verde }\end{array}$ & - & - \\
\hline 38 & $\begin{array}{l}\text { Paisaje cultural de la } \\
\text { Sierra de la Tramontana }\end{array}$ & $\begin{array}{l}\text { https://www.facebook.com/InfoMallorcane } \\
\text { t-100824359979487/ }\end{array}$ & $\begin{array}{l}\text { https://twitter.com/InfoMallorca?ref_ } \\
\text { src=twsrc\%5Etfw }\end{array}$ \\
\hline 39 & $\begin{array}{l}\text { Patrimonio del Mercurio: } \\
\text { Almadén e Idrija }\end{array}$ & - & - \\
\hline 40 & Dólmenes de Antequera & $\begin{array}{l}\text { https://www.facebook.com/antequera. } \\
\text { directaatucorazon.7?fref=ts }\end{array}$ & https://twitter.com/ATQaTuCorazon \\
\hline
\end{tabular}

Fuente: elaboración propia 
Mediante la búsqueda de las palabras clave en Facebook y Twitter: patrimonio, UNESCO, monumento, cultura y evento cultural se han identificado los eventos 2.0 gestionados, durante el periodo acotado, para fomentar la marca territorio Patrimonio de la Humanidad.

Nuestro análisis se centra en los siguientes aspectos vinculados a las redes sociales: la notoriedad y visibilidad del evento, la amplificación y viralización de su información, así como la obtención de comentarios y recomendaciones de los usuarios turísticos. Para ello, se han monitorizado tres parámetros siguiendo estudios previos realizados por Campillo, Ramos \& Castelló (2014) o Mariani, Di Felice \& Mura (2016): audiencia (seguidores y publicaciones), nivel de implicación de los usuarios en las interacciones con tres niveles de reacción de los usuarios ante las publicaciones (me gusta, compartidos y responder en Facebook; reacciones, retweets y comentarios en Twitter), así como el interés suscitado por las publicaciones, identificando las interacciones producidas por los usuarios en función del número de publicaciones.

\section{Resultados}

En los resultados de investigación se reflejan, como primera variable a analizar, los datos sobre la audiencia de los eventos a través de las publicaciones y el seguimiento de los mismos en las dos redes sociales principales, que son utilizadas de forma recurrente para difundir los eventos culturales realizados por las entidades gestoras del destino.

En el gráfico 1 se representan los eventos 2.0 de los Sitios Patrimonio Mundial difundidos a través de las redes sociales Facebook y Twitter, así como el número de publicaciones realizadas por la DMO como fuente de información primaria.

\section{Grafico 1: Eventos 2.0 desarrollados en los SPM y publicaciones en redes sociales de la roganización gestora del destino}

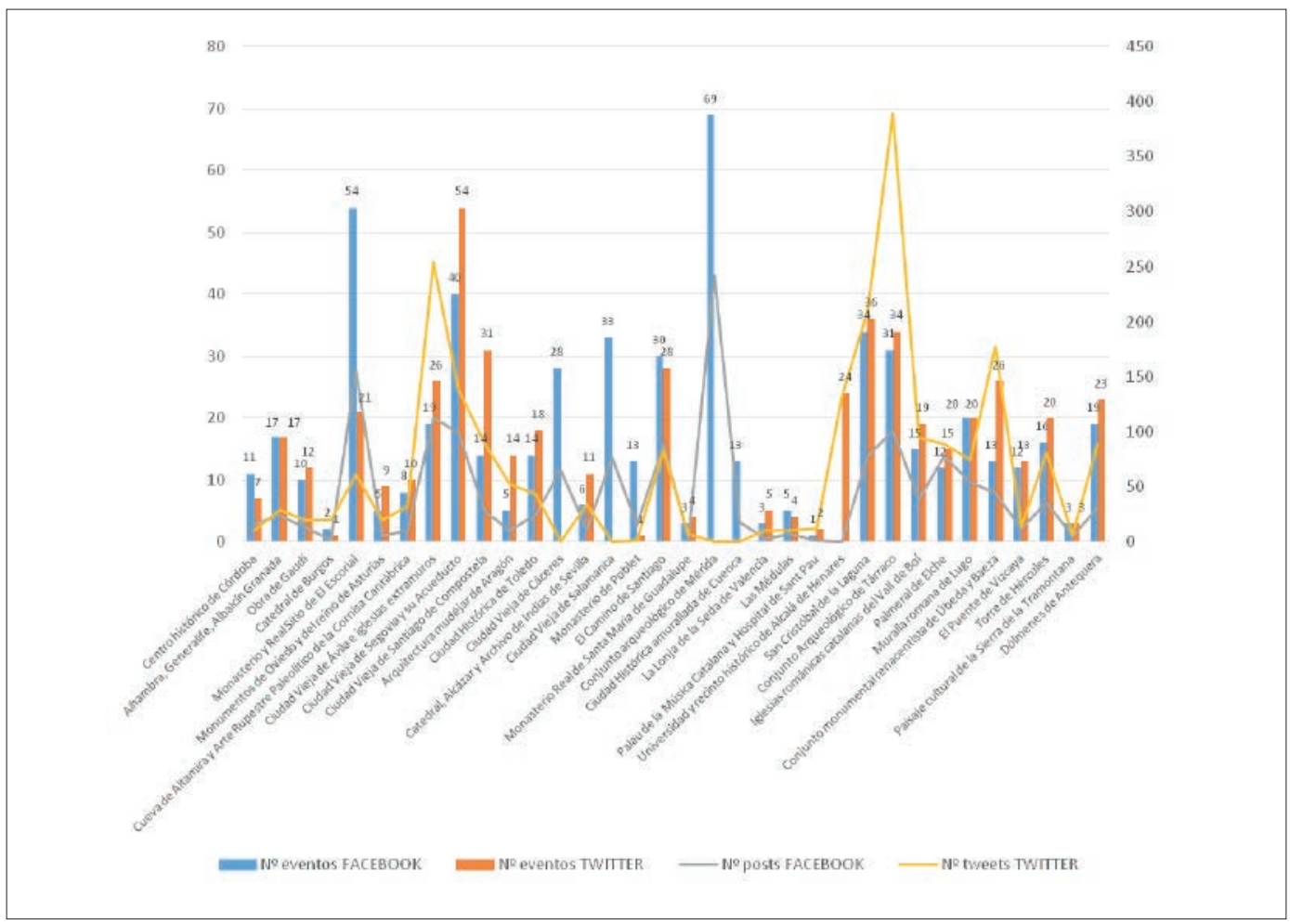

Fuente: elaboración propia 
Podemos observar cómo a partir del número de eventos 2.0 celebrados en los Sitios Patrimonio Mundial, se presentan dos realidades sumamente diferentes: por una parte, un escaso aprovechamiento de las potencialidades de las redes sociales (número de posts en Facebook o tweets en Twitter) como es el caso del Monasterio y Real Sitio del Escorial, la Ciudad Vieja de Segovia y su acueducto o el conjunto arqueológico de Mérida; por otra, una estrategia integrada de comunicación digital a través de ambas redes sumamente eficiente por parte de las DMO, en el caso de Ciudad Vieja de Ávila e Iglesia de Extramuros, Universidad y recinto histórico de Alcalá de Henares, San Cristóbal de la Laguna, conjunto histórico de Tárraco y el conjunto monumental renacentista de Úbeda y Baeza.

\section{Gráfico 2: Seguidores de los eventos 2.0 de SPM en redes sociales}

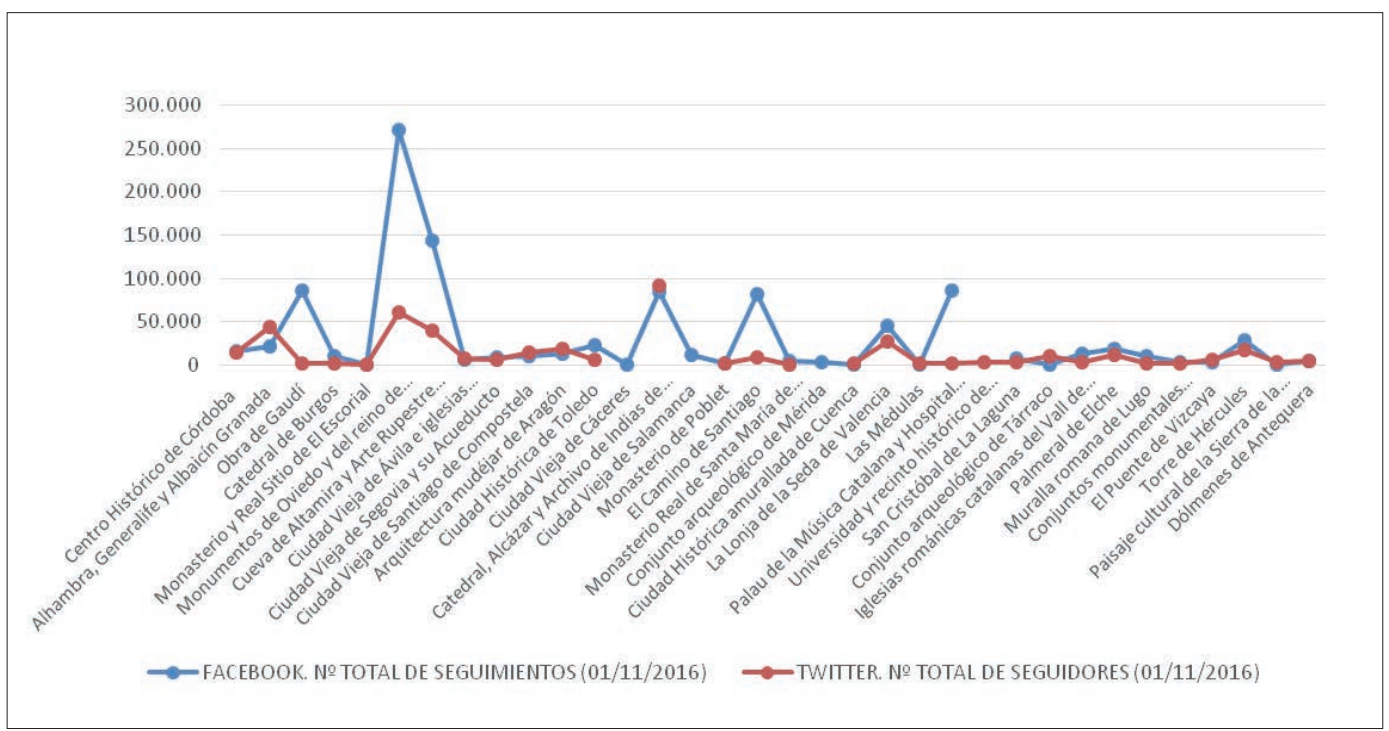

Fuente: elaboración propia

En cuanto al seguimiento de los eventos 2.0 de los Sitios Patrimonio Mundial en redes sociales, reflejado en el gráfico 2, de entre todos ellos destacan, alcanzando más de 50.000 seguidores en alguna de las dos redes analizadas, aquellos vinculados a los monumentos de Oviedo y del reino de Asturias (271.176 en Facebook; 60.900 en Twitter), la Catedral, el Alcázar y el Archivo de las Indias de Sevilla (84.107 en Facebook; 91.900 en Twitter), el Palau de la Música Catalana junto con el Hospital de Sant Pau (86.451 en Facebook; 2.382 en Twitter) o el Camino de Santiago (81.437 en Facebook; 9.369 en Twitter).

La interacción a partir de la difusión y viralidad de los eventos 2.0 de los Sitios Patrimonio Mundial, como segunda variable, se analiza en las tablas 3 y 4, estableciendo tres niveles (Campillo, Ramos y Castelló, 2014; Mariani, Di Felice \& Mura, 2016): el nivel 1, representa simplemente una reacción y por tanto se identifica con una interacción moderada; en el nivel 2, el usuario comparte la información acerca del evento, y en consecuencia existe un mayor nivel de implicación que en el nivel anterior; en el nivel 3, se supera la simple reacción o la interacción moderada que supone el compartir el evento, ya que el usuario realiza un comentario, que requiere una mayor implicación y vinculación con el evento cultural del Sitio Patrimonio Mundial. 


\section{Tabla 3: Interacción en eventos 2.0 a través de Facebook}

\begin{tabular}{|c|c|c|c|}
\hline Bienes Patrimonio Mundial Cultural & $\begin{array}{l}\text { Reacciones } \\
\text { (NIVEL 1) }\end{array}$ & $\begin{array}{c}\text { Compartido } \\
\text { (NIVEL 2) }\end{array}$ & $\begin{array}{l}\text { Comentarios } \\
\text { (NIVEL 3) }\end{array}$ \\
\hline Centro Histórico de Córdoba & 2.418 & 2.566 & 62 \\
\hline Alhambra, Generalife y Albaicín de Granada & 2.810 & 771 & 39 \\
\hline Obra de Gaudí & 11.002 & 626 & 290 \\
\hline Catedral de Burgos & 136 & 64 & 3 \\
\hline Monasterio y Real Sitio de El Escorial & 426 & 92 & 3 \\
\hline Monumentos de Oviedo y del reino de Asturias & 9.459 & 2.338 & 237 \\
\hline $\begin{array}{l}\text { Cueva de Altamira y Arte Rupestre Paleolítico de la } \\
\text { Cornisa Cantábrica }\end{array}$ & 976 & 2.278 & 147 \\
\hline Ciudad Vieja de Ávila e iglesias extramuros & 5.979 & 1.999 & 70 \\
\hline Ciudad Vieja de Segovia y su Acueducto & 2.131 & 1.808 & 48 \\
\hline Ciudad Vieja de Santiago de Compostela & 2.261 & 427 & 33 \\
\hline Arquitectura mudéjar de Aragón & 285 & 74 & 3 \\
\hline Ciudad Histórica de Toledo & 2.626 & 1.035 & 50 \\
\hline Ciudad Vieja de Cáceres & 1.302 & 877 & 47 \\
\hline Catedral, Alcázar y Archivo de Indias de Sevilla & 3.965 & 963 & 78 \\
\hline Ciudad Vieja de Salamanca & 3.011 & 946 & 39 \\
\hline Monasterio de Poblet & 153 & 14 & 2 \\
\hline El Camino de Santiago & 5.521 & 178 & 103 \\
\hline Monasterio Real de Santa María de Guadalupe & 54 & 0 & 0 \\
\hline Conjunto arqueológico de Mérida & 3.561 & 2.466 & 59 \\
\hline Ciudad Histórica amurallada de Cuenca & 202 & 42 & 4 \\
\hline La Lonja de la Seda de Valencia & 500 & 313 & 9 \\
\hline Las Médulas & 477 & 171 & 1 \\
\hline Palau de la Música Catalana y Hospital de Sant Pau & 624 & 48 & 14 \\
\hline San Cristóbal de La Laguna & 652 & 200 & 12 \\
\hline Conjunto arqueológico de Tárraco & 487 & 126 & 15 \\
\hline Iglesias románicas catalanas del Vall de Boí & 3.457 & 473 & 47 \\
\hline Palmeral de Elche & 243 & 909 & 59 \\
\hline Muralla romana de Lugo & 2.107 & 1.216 & 46 \\
\hline Conjunto monumental renacentista de Úbeda y Baeza & 667 & 176 & 27 \\
\hline El Puente de Vizcaya & 64 & 20 & 2 \\
\hline Torre de Hércules & 4.433 & 514 & 77 \\
\hline Paisaje cultural de la Sierra de la Tramontana & 7 & 0 & 0 \\
\hline \multirow[t]{2}{*}{ Dólmenes } & 1.814 & 656 & 44 \\
\hline & 73.810 & 24.386 & 1.669 \\
\hline
\end{tabular}

Fuente: elaboración propia

En la tabla 3, podemos observar la interacción que se produce a través de Facebook en los eventos vinculados al Patrimonio Mundial y su grado de intensidad. El nivel 1 representa el $74 \%$ del total de interacciones producidas (73.810); el nivel 2, el 24,4\% (24.386) y el nivel 3, el 1,6\% (1.669). Se ha calculado, a partir de los resultados obtenidos, el valor de la mediana de los tres niveles (en el nivel 1=1.302; en el nivel $2=473$; en el nivel $3=39$ ). Se identifican en la tabla (con sombreado) aquellos resultados que se encuentran situados a partir de la mediana y con valores superiores a la misma, ya que ésta representa, a nivel estadístico, el valor central en una serie determinada de datos cuantitativos que se segmentan en dos áreas de posición diferenciadas: lo que permite comparar el nivel de interacción desarrollado. Se destacan, además, los cinco valores principales en cada nivel. 
En esta serie de datos se sitúan por encima del valor estadístico de la mediana en las tres categorías o niveles, de forma simultánea, 15 Sitios Patrimonio Mundial (que representan el 37,5\% del total de los 40 SPM analizados): 1) Obra de Gaudí, 2) Monumentos de Oviedo y del reino de Asturias, 3) Ciudad Vieja de Ávila e iglesias extramuros, 4) Torre de Hércules, 5) Catedral, Alcázar y Archivo de Indias de Sevilla, 6) Conjunto arqueológico de Mérida, 7) Iglesias románicas catalanas del Vall de Boí, 8) Ciudad Vieja de Salamanca, 9) Alhambra, Generalife y Albaicín de Granada, 10) Ciudad Histórica de Toledo, 11) Centro Histórico de Córdoba, 12) Ciudad Vieja de Segovia y su Acueducto, 13) Muralla romana de Lugo, 14) Dólmenes de Antequera y 15) Ciudad Vieja de Cáceres.

\section{Tabla 4: Interacción en eventos 2.0 vinculados a los SPM a través de Twitter}

\begin{tabular}{|c|c|c|c|}
\hline Bienes Patrimonio Mundial Cultural & $\begin{array}{l}\text { Reacciones: } \\
\text { me gusta } \\
\text { (NIVEL 1) }\end{array}$ & $\begin{array}{c}\text { Compartir/ } \\
\text { Retweet } \\
\text { (NIVEL 2) }\end{array}$ & $\begin{array}{l}\text { Responder: } \\
\text { comentarios/ } \\
\text { respuestas } \\
\text { (NIVEL 3) }\end{array}$ \\
\hline Centro Histórico de Córdoba & 149 & 229 & 0 \\
\hline Alhambra, Generalife y Albaicín de Granada & 268 & 234 & 4 \\
\hline Obra de Gaudí & 55 & 38 & 2 \\
\hline Catedral de Burgos & 56 & 52 & 1 \\
\hline Monasterio y Real Sitio de El Escorial & 1 & 4 & 0 \\
\hline Monumentos de Oviedo y del reino de Asturias & 740 & 558 & 15 \\
\hline $\begin{array}{l}\text { Cueva de Altamira y Arte Rupestre Paleolítico de la Cornisa } \\
\text { Cantábrica }\end{array}$ & 587 & 448 & 11 \\
\hline Ciudad Vieja de Ávila e iglesias extramuros & 1285 & 1343 & 34 \\
\hline Ciudad Vieja de Segovia y su Acueducto & 397 & 361 & 12 \\
\hline Ciudad Vieja de Santiago de Compostela & 181 & 113 & 5 \\
\hline Arquitectura mudéjar de Aragón & 352 & 235 & 5 \\
\hline Ciudad Histórica de Toledo & 148 & 139 & 4 \\
\hline Catedral, Alcázar y Archivo de Indias de Sevilla & 599 & 465 & 4 \\
\hline Monasterio de Poblet & 1 & 3 & 0 \\
\hline El Camino de Santiago & 524 & 301 & 1 \\
\hline Monasterio Real de Santa María de Guadalupe & 1 & 0 & 0 \\
\hline Ciudad Histórica amurallada de Cuenca & 0 & 0 & 0 \\
\hline La Lonja de la Seda de Valencia & 138 & 113 & 4 \\
\hline Las Médulas & 13 & 18 & 0 \\
\hline Palau de la Música Catalana y Hospital de Sant Pau & 15 & 16 & 0 \\
\hline Universidad y recinto histórico de Alcalá de Henares & 401 & 477 & 8 \\
\hline San Cristóbal de La Laguna & 266 & 171 & 5 \\
\hline Conjunto arqueológico de Tárraco & 656 & 554 & 15 \\
\hline Iglesias románicas catalanas del Vall de Boí & 662 & 240 & 8 \\
\hline Palmeral de Elche & 396 & 355 & 6 \\
\hline Muralla romana de Lugo & 178 & 182 & 2 \\
\hline Conjuntos monumentales renacentistas de Úbeda y Baeza & 416 & 276 & 3 \\
\hline El Puente de Vizcaya & 25 & 26 & 0 \\
\hline Torre de Hércules & 413 & 292 & 7 \\
\hline Paisaje cultural de la Sierra de la Tramontana & 0 & 0 & 0 \\
\hline \multirow[t]{2}{*}{ Dólmenes de Antequera } & 277 & 350 & 12 \\
\hline & 9200 & 7593 & 168 \\
\hline
\end{tabular}

Fuente: elaboración propia 
En la tabla 4, podemos observar que en la interacción global de los eventos 2.0 que se produce vía Twitter, el nivel 1 representa un 54,2\%, frente al nivel 2 (44,8\%) y el nivel 3 (1\%). Por otra parte, se calcula el valor de la mediana de los tres niveles (nivel 1=266; nivel $2=229$; nivel $3=4$ ), para segmentar la serie de datos en dos áreas de posición, tal y como se ha procedido anteriormente en el caso de Facebook: se señalan aquellos resultados que se encuentran situados a partir de la mediana y con valores superiores a la misma. Así mismo, se destacan, al igual que en la tabla 3, los cinco valores principales por niveles.

En esta serie de datos se sitúan por encima del valor estadístico de la mediana 12 Sitios Patrimonio Mundial con interacción simultánea a través de los tres niveles de intensidad (que representan el 30\% sobre el total de los 40 SPM): 1) Ciudad Vieja de Ávila e iglesias extramuros, 2) Monumentos de Oviedo y del reino de Asturias, 3) Iglesias románicas catalanas del Vall de Boí, 4) Conjunto arqueológico de Tárraco, 5) Catedral, Alcázar y Archivo de Indias de Sevilla, 6) Cueva de Altamira y Arte Rupestre Paleolítico de la Cornisa Cantábrica, 7) Torre de Hércules, 8) Universidad y recinto histórico de Alcalá de Henares, 9) Ciudad Vieja de Segovia y su Acueducto, 10) Palmeral de Elche, 11) Arquitectura mudéjar de Aragón y 12) Dólmenes de Antequera.

Como tercera variable se analiza el interés que han suscitado los eventos de carácter cultural; dicho parámetro se define a partir del número de interacciones producidas por los usuarios divididas entre el número de publicaciones efectuadas por las entidades gestoras de los Sitios Patrimonio Mundial en las dos redes sociales analizadas. Se establece, según los puntos de inflexión de los resultados que se reflejan en los gráficos 3 y 4 , una clasificación a partir de tres categorías $(A=$ interés elevado, $B=$ interés moderado y $C=$ escaso o nulo interés).

\section{Gráfico 3: Interés sobre los eventos 2.0 através de Facebook (interacciones/publicaciones)}

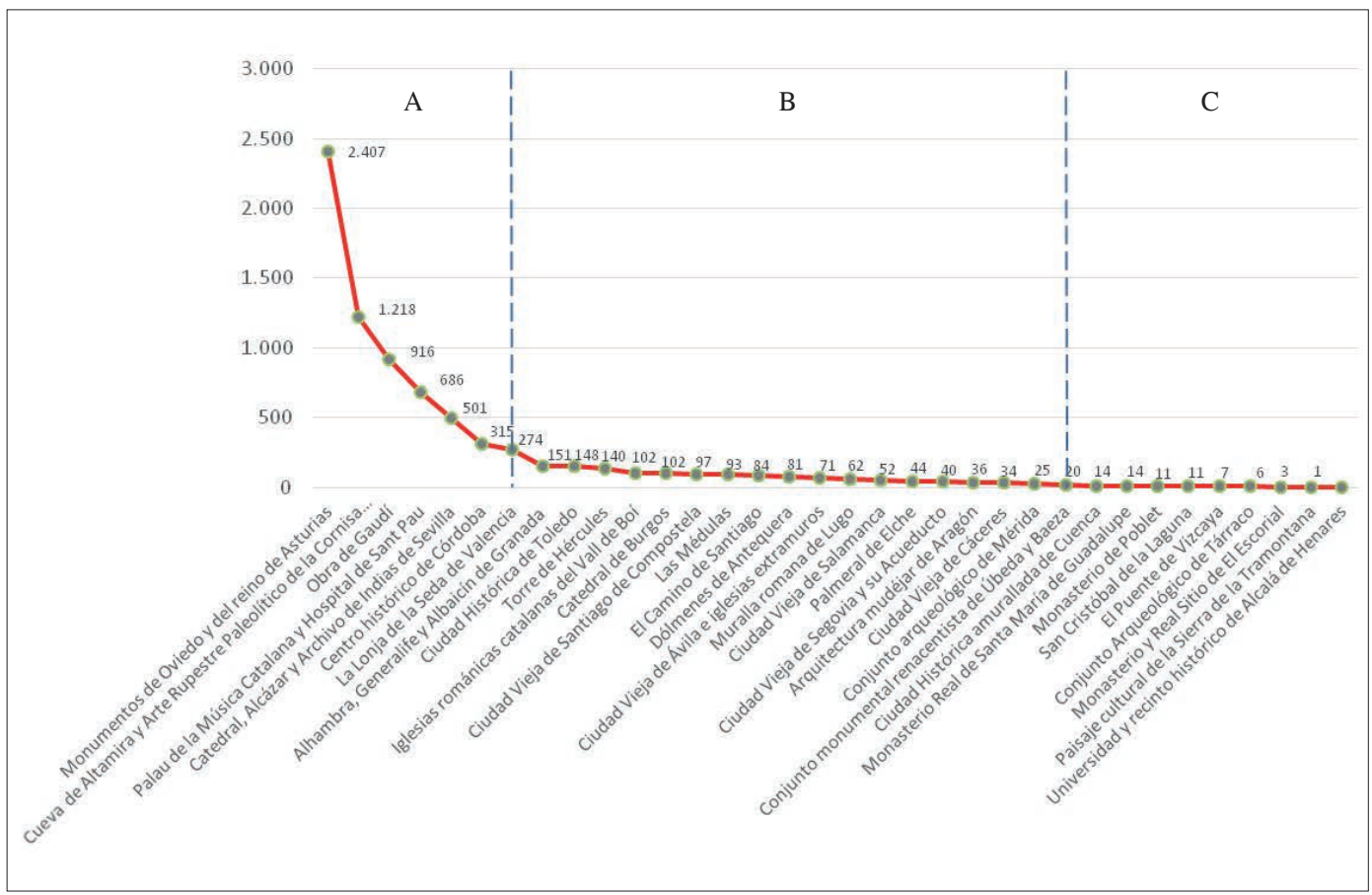

Fuente: elaboración propia

En el gráfico 3 aparecen como eventos 2.0 a través de la red social Facebook, con categoría A, en cuanto al interés suscitado, y en orden descendente, aquellos vinculados a los Monumentos de Oviedo y del reino de Asturias, la Cueva de Altamira y el Arte Rupestre de la Cornisa Cantábrica, Obra de Gaudí, el Palau de la Música Catalana y el Hospital de Sant Pau, la Catedral, el Alcázar y el Archivo 
de Indias de Sevilla, el Centro Histórico de Córdoba y la Lonja de la Seda de Valencia; en la categoría $B$, la Alhambra, el Generalife y el Albaicín de Granada, la Ciudad Histórica de Toledo, la Torre de Hércules, las iglesias románicas catalanas del Vall de Boí, la Catedral de Burgos, la Ciudad Vieja de Santiago de Compostela, las Médulas, el Camino de Santiago, los Dólmenes de Antequera, la Ciudad Vieja de Ávila e iglesias extramuros, la Muralla romana de Lugo, la Ciudad Vieja de Salamanca, El Palmeral de Elche, la Ciudad Vieja de Segovia y su Acueducto, la Arquitectura Mudéjar de Aragón, la Ciudad Vieja de Cáceres, el Conjunto arqueológico de Mérida y el Conjunto Monumental Renacentista de Úbeda y Baeza; en la categoría C, la Ciudad Histórica Amurallada de Cuenca, el Monasterio Real de Santa María de Guadalupe, el Monasterio de Poblet, San Cristóbal de la Laguna, El Puente de Vizcaya, el Conjunto Arqueológico de Tárraco, el Monasterio y el Real Sitio de El Escorial, el Paisaje Cultural de la Sierra de la Tramontana y la Universidad y recinto Histórico de Alcalá de Henares.

\section{Gráfico 4: Interés sobre los eventos 2.0 através de Twitter (interacciones/publicaciones)}

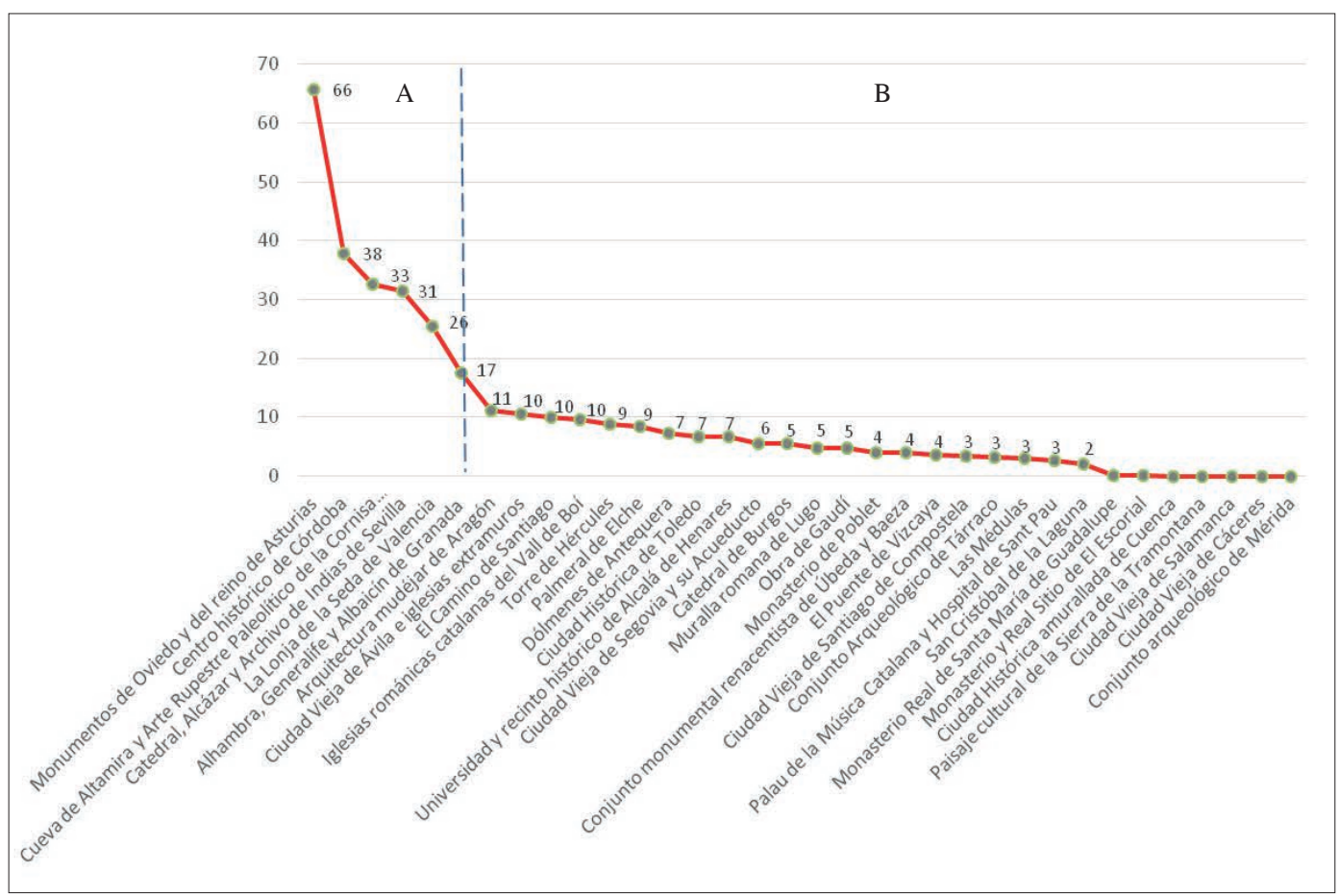

Fuente: elaboración propia

En el gráfico 4, aparecen como eventos 2.0 a través de la red social Twitter, con categoría A, aquellos vinculados a los Monumentos de Oviedo y del reino de Asturias, el Centro Histórico de Córdoba, la Cueva de Altamira y el Arte rupestre de la cornisa cantábrica, la Catedral, el Alcázar y el Archivo de Indias de Sevilla, la Lonja de la Seda de Valencia, la Alhambra, el Generalife y el Albaicín de Granada; en la categoría B, y en orden descendente, la Arquitectura Mudéjar de Aragón, la Ciudad Vieja de Ávila e iglesias extramuros, el Camino de Santiago, las iglesias románicas catalanas del Vall de Boí, la Torre de Hércules, El Palmeral de Elche, los Dólmenes de Antequera, la Ciudad Histórica de Toledo, la Universidad junto con el Recinto Histórico de Alcalá de Henares, la Ciudad Vieja de Segovia y su Acueducto, la Catedral de Burgos, la Muralla romana de Lugo, Obra de Gaudí, el Monasterio de Poblet, el Conjunto Monumental Renacentista de Úbeda y Baeza, El Puente de Vizcaya, la Ciudad Vieja de Santiago de Compostela, el Conjunto Arqueológico de Tárraco, las Médulas, el Palau de la Música Catalana y el Hospital de Sant Pau, así como San Cristóbal de la Laguna; en la categoría C, el Monasterio Real de Santa María de Guadalupe, el Monasterio y el Real Sitio de El Escorial, la Ciudad 
Histórica Amurallada de Cuenca, el Paisaje Cultural de la Sierra de la Tramontana, la Ciudad Vieja de Salamanca, la Ciudad Vieja de Cáceres y el Conjunto arqueológico de Mérida.

Tras el análisis efectuado de las tres variables: audiencia (publicaciones y seguidores), interacción de nivel 1, 2 y 3 en Facebook y Twitter, así como el interés suscitado por los eventos 2.0 en ambas redes, se configura un ranking para establecer la eficacia de las DMO, cuando utilizan en sus estrategias de marketing este recurso estratégico para reforzar la marca territorio Sitio Patrimonio Mundial. En la elaboración del ranking, para la variable audiencia (como publicaciones y seguimientos) se han asignado valores descendentes para ambos parámetros (entre 3 y 1) que determinan un índice de audiencia elevada, media y escasa o nula (gráficos 1 y 2); en la variable interacción, valores descendentes en Facebook (entre 19 y 1 ) y Twitter (entre 20 y 1), a partir del indicador estadístico de la mediana en los tres niveles de interacción cuando se presentan de forma simultánea (tablas 3 y 4); en la variable interés, valores descendentes (entre 3 y 1) en ambas redes sociales según el interés elevado, moderado y escaso o nulo interés (gráficos 3 y 4 ).

\section{Tabla 5: Ranking de eficacia de los eventos 2.0 en las estrategias de marketing de destino de los Sitios Patrimonio Mundial Cultural en España}

\begin{tabular}{|c|c|c|c|c|c|c|c|c|c|}
\hline & $\begin{array}{c}\text { Bienes Património } \\
\text { Mundial }\end{array}$ & Publicaciones & Segumientos & $\begin{array}{l}\text { Interacción } \\
\text { (F) }\end{array}$ & $\begin{array}{l}\text { Interacción } \\
\text { (T) }\end{array}$ & \begin{tabular}{|c|}
$\begin{array}{c}\text { Interés } \\
\text { (F) }\end{array}$ \\
\end{tabular} & $\begin{array}{c}\text { Interés } \\
\text { (T) }\end{array}$ & Puntuación & Categoría \\
\hline 1 & $\begin{array}{l}\text { Monumientos de } \\
\text { Oviedo y del reino de } \\
\text { Asturias }\end{array}$ & 2 & 2 & 18 & 19 & 3 & 3 & 47 & A \\
\hline 2 & $\begin{array}{l}\text { Ciudad Vieja de Ávila } \\
\text { e iglesias extramuros }\end{array}$ & 3 & 1 & 17 & 20 & 2 & 2 & 45 & A \\
\hline 3 & $\begin{array}{l}\text { Catedral, Alcázar y } \\
\text { Archivo de Indias de } \\
\text { Sevilla }\end{array}$ & 2 & 2 & 15 & 16 & 3 & 3 & 41 & A \\
\hline 4 & $\begin{array}{l}\text { Iglesias románicas } \\
\text { catalanas del Vall } \\
\text { de Boí }\end{array}$ & 2 & 1 & 13 & 18 & 2 & 2 & 38 & A \\
\hline 5 & Torre de Hércules & 2 & 1 & 16 & 14 & 2 & 2 & 37 & $\mathrm{~A}$ \\
\hline 6 & Obra de Gaudi & 2 & 1 & 19 & 0 & 3 & 2 & 27 & $\mathrm{~A}$ \\
\hline 7 & $\begin{array}{l}\text { Cueva de Altamira } \\
\text { y Arte Rupestre } \\
\text { Paleolítico C. } \\
\text { Cantábrica } \\
\end{array}$ & 2 & 1 & 2 & 15 & 3 & 3 & 26 & A \\
\hline 8 & $\begin{array}{l}\text { Ciudad Vieja } \\
\text { de Segovia y su } \\
\text { Acueducto } \\
\end{array}$ & 1 & 1 & 8 & 12 & 2 & 2 & 26 & A \\
\hline 9 & $\begin{array}{l}\text { Alhambra, Generalife } \\
\text { y Albaicín de Granada }\end{array}$ & 2 & 1 & 11 & 6 & 2 & 3 & 25 & A \\
\hline 10 & $\begin{array}{l}\text { Conjunto arqueológico } \\
\text { de Tárraco }\end{array}$ & 3 & 1 & 0 & 17 & 1 & 2 & 24 & A \\
\hline 11 & $\begin{array}{l}\text { Dólmenes de } \\
\text { Antequera }\end{array}$ & 2 & 1 & 6 & 9 & 2 & 2 & 22 & B \\
\hline 12 & $\begin{array}{l}\text { Centro Histórico de } \\
\text { Córdoba } \\
\end{array}$ & 2 & 1 & 9 & 3 & 3 & 3 & 21 & B \\
\hline 13 & El Camino de Santiago & 2 & 2 & 4 & 8 & 2 & 2 & 20 & $\mathrm{~B}$ \\
\hline 14 & $\begin{array}{l}\text { Universidad y recinto } \\
\text { histórico de Alcalá de } \\
\text { Henares }\end{array}$ & 3 & 1 & 0 & 13 & 1 & 2 & 20 & B \\
\hline 15 & $\begin{array}{l}\text { Ciudad Histórica de } \\
\text { Toledo }\end{array}$ & 2 & 1 & 10 & 2 & 2 & 2 & 19 & B \\
\hline 16 & $\begin{array}{l}\text { Conjunto arqueológico } \\
\text { de Mérida }\end{array}$ & 1 & 1 & 14 & 0 & 2 & 1 & 19 & B \\
\hline 17 & Palmeral de Elche & 2 & 1 & 1 & 11 & 2 & 2 & 19 & $\mathrm{~B}$ \\
\hline 18 & $\begin{array}{l}\text { Ciudad Vieja de } \\
\text { Salamanca } \\
\end{array}$ & 2 & 1 & 12 & 0 & 2 & 1 & 18 & B \\
\hline 19 & $\begin{array}{l}\text { Arquitectura mudéjar } \\
\text { de Aragón }\end{array}$ & 2 & 1 & 0 & 10 & 2 & 2 & 17 & B \\
\hline 20 & $\begin{array}{l}\text { Conjuntos } \\
\text { monumentales } \\
\text { renacentistas de } \\
\text { Úbeda y Baeza }\end{array}$ & 3 & 1 & 0 & 7 & 2 & 2 & 15 & B \\
\hline
\end{tabular}




\begin{tabular}{|c|c|c|c|c|c|c|c|c|c|}
\hline 21 & $\begin{array}{l}\text { Ciudad Vieja } \\
\text { de Santiago de } \\
\text { Compostela }\end{array}$ & 2 & 1 & 3 & 4 & 2 & 2 & 14 & $\mathrm{C}$ \\
\hline 22 & $\begin{array}{l}\text { Muralla romana de } \\
\text { Lugo }\end{array}$ & 2 & 1 & 7 & 0 & 2 & 2 & 14 & $\mathrm{C}$ \\
\hline 23 & $\begin{array}{l}\text { San Cristóbal de La } \\
\text { Laguna }\end{array}$ & 3 & 1 & 0 & 5 & 1 & 2 & 12 & $\mathrm{C}$ \\
\hline 24 & $\begin{array}{l}\text { Ciudad Vieja de } \\
\text { Cáceres }\end{array}$ & 2 & 1 & 5 & 0 & 2 & 1 & 11 & $\mathrm{C}$ \\
\hline 25 & $\begin{array}{l}\text { La Lonja de la Seda de } \\
\text { Valencia }\end{array}$ & 2 & 1 & 0 & 1 & 3 & 3 & 10 & $\mathrm{C}$ \\
\hline 26 & $\begin{array}{l}\text { Palau de la Música } \\
\text { Catalana y Hospital } \\
\text { de Sant Pau }\end{array}$ & 2 & 2 & 0 & 0 & 3 & 2 & 9 & $\mathrm{C}$ \\
\hline 27 & Catedral de Burgos & 2 & 1 & 0 & 0 & 2 & 2 & 7 & $\mathrm{C}$ \\
\hline 28 & Las Médulas & 2 & 1 & 0 & 0 & 2 & 2 & 7 & $\mathrm{C}$ \\
\hline 29 & Monasterio de Poblet & 2 & 1 & 0 & 0 & 1 & 2 & 6 & $\mathrm{C}$ \\
\hline 30 & El Puente de Vizcaya & 2 & 1 & 0 & 0 & 1 & 2 & 6 & $\mathrm{C}$ \\
\hline 31 & $\begin{array}{l}\text { Monasterio Real } \\
\text { de Santa María de } \\
\text { Guadalupe }\end{array}$ & 2 & 1 & 0 & 0 & 1 & 1 & 5 & D \\
\hline 32 & $\begin{array}{l}\text { Ciudad Histórica } \\
\text { amurallada de Cuenca }\end{array}$ & 2 & 1 & 0 & 0 & 1 & 1 & 5 & D \\
\hline 33 & $\begin{array}{l}\text { Paisaje cultural } \\
\text { de la Sierra de la } \\
\text { Transmontana }\end{array}$ & 2 & 1 & 0 & 0 & 1 & 1 & 5 & D \\
\hline 34 & $\begin{array}{l}\text { Monasterio y Real } \\
\text { Sitio de El Escorial }\end{array}$ & 1 & 1 & 0 & 0 & 1 & 1 & 4 & $\mathrm{D}$ \\
\hline 35 & $\begin{array}{l}\text { Monasterios de San } \\
\text { Millán de Yuso y de } \\
\text { Suso }\end{array}$ & 0 & 0 & 0 & 0 & 0 & 0 & 0 & $\mathrm{D}$ \\
\hline 36 & $\begin{array}{l}\text { Yacimientos de Arte } \\
\text { Rupestre Prehistórico } \\
\text { Valle del Côa/Sieg. }\end{array}$ & 0 & 0 & 0 & 0 & 0 & 0 & 0 & D \\
\hline 37 & $\begin{array}{l}\text { Arte rupestre del Arco } \\
\text { Mediterráneo de la } \\
\text { Península Ibérica }\end{array}$ & 0 & 0 & 0 & 0 & 0 & 0 & 0 & D \\
\hline 38 & $\begin{array}{l}\text { Cuenca arqueológica } \\
\text { de Atapuerca }\end{array}$ & 0 & 0 & 0 & 0 & 0 & 0 & 0 & D \\
\hline 39 & $\begin{array}{l}\text { Paisaje cultural de } \\
\text { Aranjuez }\end{array}$ & 0 & 0 & 0 & 0 & 0 & 0 & 0 & D \\
\hline 40 & $\begin{array}{l}\text { Patrimonio del } \\
\text { Mercurio: Almadén } \\
\text { e Idrija }\end{array}$ & 0 & 0 & 0 & 0 & 0 & 0 & 0 & $\mathrm{D}$ \\
\hline
\end{tabular}

A partir de este ranking se establecen cuatro categorías para identificar la eficacia de las organizaciones gestoras del destino en la organización, ejecución y difusión de los eventos culturales vinculados a los Sitios Patrimonio Mundial: $A=$ eficacia muy alta (representada por los Sitios Patrimonio Mundial que se sitúan entre la posición 1-10); B= eficacia alta (posición 11-20); C=eficacia mejorable (posición 21-30); $D=$ escasa o nula eficacia (posición 31-40).

Los resultados de investigación obtenidos permiten afirmar que la eficacia en las estrategias de promocomercialización de los bienes culturales, a través de los eventos 2.0 , se manifiesta de forma sumamente heterogénea en nuestro país, ya que su implementación presenta diferentes niveles de consolidación. En consecuencia, consideramos que para reforzar la marca territorio SPM, resulta imprescindible establecer una estrategia de difusión de los eventos turísticos, coherentemente planificada por parte de las organizaciones gestoras del destino, en la que se integren, de forma sistematizada, los medios sociales con el resto de canales de comunicación offline. En este sentido, en la elaboración del ranking de las DMO se refleja, de forma integrada, el nivel de eficacia de las estrategias de comunicación digital de los eventos 2.0 vinculados al patrimonio histórico y cultural en España. 


\section{Conclusiones}

El marketing turístico 2.0 ha transformado, desde hace aproximadamente una década, las estrategias de promoción y comercialización de los Sitios Patrimonio Mundial reconocidos por la UNESCO. Tales estrategias no sólo deben contribuir a una mayor rentabilidad entre la oferta y la demanda del sector, sino a una sostenibilidad suficiente de los territorios que permita garantizar la preservación de los bienes patrimoniales y culturales. La declaración del año 2017, por parte de la Asamblea General de las Naciones Unidas, como Año Internacional del Turismo Sostenible para el Desarrollo, pone de manifiesto el potencial de la actividad turística para conseguir los objetivos de la Agenda 2030 del Desarrollo Sostenible. Resulta imprescindible, en este sentido, un cambio en las políticas públicas, en las prácticas de los principales agentes del sector y en los comportamientos de los consumidores que favorezcan la sostenibilidad del sector turístico (UNWTO, 2016).

Los eventos culturales integrados en las estrategias de promocomercialización de los territorios se difunden a través de redes sociales o plataformas multimedia, y se erigen como relevantes recursos turísticos coyunturales que producen, por una parte, importantes sinergias con la oferta estructural realizada por el destino; por otra, la desestacionalización de la demanda con un aumento significativo del índice de visitas y pernoctaciones. En este sentido, la planificación y el desarrollo de los eventos culturales vinculados al patrimonio debe realizarse en clave de eficacia, identificación con el destino y su sostenibilidad como valor intrínseco.

En esta investigación se presenta una radiografía de la visibilidad, notoriedad e interés que suscitan los eventos 2.0 de los 40 Sitios Patrimonio Mundial analizados. Las cuatro categorías propuestas para las DMO, nos indican las diferencias sustanciales que existen respecto a la difusión y viralización de los eventos 2.0. Por tanto, como metodología para la planificación de estos recursos intencionales y estratégicos, es posible identificar, por parte de las entidades gestoras del destino, fortalezas, debilidades, amenazas y oportunidades que permitan establecer propuestas de continuidad, evolución y mejora en la difusión de los eventos culturales 2.0 vinculados a los bienes históricos, culturales y patrimoniales.

Tras este análisis, y a partir de la delimitación de nuestra propuesta, nos planteamos como futuras líneas de investigación establecer la correlación existente entre el índice de eficacia en la comunicación y viralidad de los eventos 2.0 con los resultados socio-económicos del sector turístico en los destinos SPM en España; así mismo, a partir de los bienes culturales analizados, la ampliación del objeto de estudio a las restantes categorías que representan los bienes naturales y mixtos declarados por la UNESCO Patrimonio de la Humanidad, permitiría establecer una radiografía más amplia y exhaustiva de nuestro ámbito de investigación.

\section{Relación de eventos difundidos a través de Facebook (F) y Twitter (T)}

Centro histórico de Córdoba: 36 Feria del Libro Antiguo (F/T), Concurso de cartelería sobre la protección medioambiental en los cascos históricos de las ciudades que conforman el Grupo de Ciudades Patrimonio de la Humanidad de España (F/T), Conmemoración Día Internacional del Patrimonio Mundial (F/T), Patio de verano: Noches de Ramadán (F/T), XXI Aniversario de la inscripción en la lista del Patrimonio Mundial (F/T), Congreso Cocina Conventual (F), Conmemoración Día Internacional del Turismo (F), Córdoba Califato Gourmet (F), Exposición de dibujos realizados por expertos del Conjunto Arqueológico de Madinat al-Zahra (F), Magna Mariana (F), Patio de primavera (F), Día de la Solidaridad de las ciudades Patrimonio Mundial de la Humanidad (T) y Jornada de Calidad Turística (T).

Alhambra, Generalife y Albaicín de Granada: "La ciudad del Agua": proyecto promovido por el Patronato de la Alhambra y Generalife que integra "12 postales sonoras de la Alhambra y del Generalife" y contenidos fotográficos y videográficos (F/T), Alhambra: visita gratuita guiada para residentes (F/T), Aperturas temporales de espacios normalmente cerrados (mensuales) (F/T), Charlas temáticas en el Museo de la Alhambra (F/T), Conmemoración Día de la Hispanidad (F/T), Conmemoración Día de la Solidaridad de las Ciudades Patrimonio Mundial (F/T), Conmemoración Día Internacional de los Monumentos (F/T), CxM Alhambra Sacromonte (F/T), Exposición con las mejores fotografías del concurso organizado por el Patronato de la Alhambra y la Asociación de Vecinos del Bajo Albaicín (F/T), Fiestas de San Miguel 2016, en el Albaicín (F/T), La Alhambra en clave: Conciertos, recitales, etc. (F/T), Programa Lorca y Granada (F/T), Exposición "Granada: capricho de la Naturaleza y la Historia" en Cuarto Real. (F/T), Noches del Museo (F/T), Verano cultural: Festival Internacional de Música y Danza, concierto, 
flamenco, teatro, Agenda (F/T), Verbena en honor a la Virgen de la Aurora (F/T), Museo de la Alhambra: visita guiada gratuita y actividades para niños (dibujo) (F), Seminario permanente de Patrimonio organizado por las Iglesias del Albaicín (F), V Noche Sahiliana (F), Visita guiada "Las Leyendas en el entorno de la Alhambra” (T) y Conmemoración Día del Patrimonio Mundial (T).

Obra de Gaudí: Casa Batlló "Noches mágicas" (F/T), Concurso Instagram (F/T), Conmemoración Día Mundial del Sida (F/T), Decoración navideña fachada La Pedrera (F/T), Feria de Navidad en la Sagrada Familia (F/T), Noche de los museos (F/T), Noches de verano en el Palau Güell (F/T), Jornada de puertas abiertas Palau Güell (F/T), Sant Jordi: tematización, decoración fachada Casa Batlló (F/T), Iluminación especial fachada Casa Batlló (F), Visita teatralizada a la Casa Batlló (F), La Pedrera de Gaudí, "Los Orígenes" (T) y Ciclo Dansa Ara (T).

Catedral de Burgos: Fitur 2016 (F/T) y Vuelta a Burgos (F).

Monasterio y Real Sitio de El Escorial: Taller recicla-juegos (F/T), XI Festival Folklórico "El Cimborrio" (F/T), "Tiempo de San Lorenzo" (F/T), Carnaval (F/T), Ciclo de piano en los Reales Sitios - San Lorenzo y El Escorial (F/T), Conciertos (F/T), Exhibiciones de cetrería (F/T), Exposición "Pasión por la acuarela" (F/T), Exposición: Fondo municipal de obras de arte 2015 y un recorrido por todas las exposiciones del año (F/T), Festival de verano (F/T), Festividad de San Antón (F/T), Fiestas patronales (F/T), Fitur 2016 (F/T), III Festival Cortoespaña (F/T), Jornadas Gastronómicas y Ruta de Tapas San Lorenzo de El Escorial, micológicas y de bayas. Ruta de tapas San Lorenzo de El Escorial: Bacalao y Torrijas y Ruta tapas Romeras (F/T), Los Cursos de Verano de la Complutense en San Lorenzo (F/T), Navidad 2015 (F/T), Nueva edición de la Montaña solidaria Races Trail Running (F/T), Nueva edición de la Ruta Imperial, Imperial BikeTour (F/T), Tercer Centenario del nacimiento de Carlos III (F/T), XV Media Maratón de San Lorenzo de El Escorial (F/T), $1^{a}$ edición Imagina Escorial (F), Campaña promocional de Comunidad de Madrid (F), Campaña el Comercio sobre Ruedas III (F), Celebración del Capítulo de la Real y Militar Orden de San Hermenegildo (F), Ciclo de Teatro Coliseo Clásico, en el Real Coliseo de Carlos III de San Lorenzo de El Escorial (F), Concierto "Carmina Burana" del CIM (F), Concierto al aire libre de bossa y blues (F), Concierto de Tonadillas (F), Concierto de música barroca en los jardines de la Casita del Infante Don Gabriel (F), Concurso en RRSS: Facebook e Instagram (F), Conmemoración Día Mundial de la Justicia Social y concierto (F), Conmemoración Día Mundial del Turismo (F), Ecosalud 2016 (F), Feria del libro Antiguo y de ocasión (F), Festival de Teatro del 2 de mayo (F), Festividad de San Sebastián (F), Fiestas del Zaburdón (F), I Semana Internacional del Libro "EscoLibro" (F), Lágrimas de San Lorenzo (F), Minuto de silencio: atentados de Bruselas (F), Parque de atracciones de Madrid: "Día especial de San Lorenzo de El Escorial” (F), Rock\&Run 2016 (F), Rodaje de un reality (F), Romería Virgen de Gracia (F), Semana Santa (F), Torneo de Golf Challenge Tour Europa (F), V centenario de la muerte de Hieronymus van Acken Bosch, El Bosco (F/T), V Festival Wagneriano de San Lorenzo de El Escorial (F), XII Muestra Folclórica del Grupo la Aldaba (F), XIX Torneo de Pádel \& Tenis Benéfico Virgen de Gracia (F), XVII Premio de Grabado "San Lorenzo del Escorial” (F), y XXX Concurso de pintura rápida "Manuel Viola" (F).

Monumentos de Oviedo y del reino de Asturias: 30 Aniversario de la Declaración del Prerrománico Asturiano (F/T), Día Internacional de los Monumentos y Sitios (F/T), Visita blogueros y escritores de viajes irlandeses (F/T), Vuelta ciclista de Asturias: presentación (F/T), I Concurso de Fotografía "Asturias Paraíso Natural" (F/T), Día Internacional del Guía de Turismo (T), Jornadas Científicas sobre Prerrománico Asturiano en Oviedo (T), Talleres en el Centro del Prerrománico Asturiano (T), y Concurso en Instagram: "Otoño en Asturias" (T).

Cueva de Altamira y Arte Rupestre Paleolítico de la Cornisa Cantábrica: Visitas Culturales guiadas gratuitas programa incentivARTE (F/T), Intur 2015: I Foro Empresarial de Innovación y Tecnologías turísticas (F/T), Fitur 2016 (F/T), Estreno tráiler de Altamira Película (F/T), Semana Santa (F/T), Conmemoración Día Mundial de la Salud (F/T), Concurso entre visitantes Museo Altamira (F/T), Puente de diciembre puertas abiertas (F), Conmemoración Día Internacional de la Mujer (T), y Día del Medio Ambiente (T).

Ciudad Vieja de Ávila e iglesias extramuros: 30 aniversario de la Declaración como Patrimonio Mundial (F/T), Fitur 2016 (F/T), Acto oficial en Memoria de las Víctimas del Holocausto (F/T), Feria de Turismo de Hamburgo (F/T), Rodaje serie documental "Ciudades españolas Patrimonio Mundial" RTVE (F/T), Rutas, visitas guiadas, teatralizadas: "Ávila Palaciega", "Ávila Patrimonio de la Humanidad", "Ávila Judía”, "Ávila de Leyenda", "Joyas abulenses", visita nocturna teatralizada a la muralla, rutas e-bike, etc. (F/T), III Ciclo de Música de Cámara del Grupo Ciudades Patrimonio de la Humanidad (F/T), Semana Santa (F/T), Conmemoración Día de la Muralla (F/T), Talleres infantiles: de arqueología, de paisajes, "Por las huellas de mi niñez", etc. (F/T), Conmemoración Nacimiento de Santa Teresa (F/T), Centenario de la Llegada 
de Guido Caprotti (F/T), Simposium internacional de murallas en Ávila (F/T), IV Muestra de Estatuas Vivientes Ciudad de Ávila (F/T), Festival de Música Internacional Abvlensis (F/T), Semana Europea de la Cultura Judía (F/T), Ávila Mágica (F), Ávila Medieval (F), XXVIII Muestra de Teatro Ciudad de Ávila (T), Feria de Turismo de Bélgica (T), Seminario-Taller Ávila: Presente y desafío de futuro de un destino turístico (T), Día internacional de los Museos (T), Ávila en Tapas (T), Concierto de Manuel Carrasco (T), XX Jornadas Medievales. Ávila Medieval: mercado, actuaciones, representaciones, pregón, etc. (T), Festival Internacional de Circo de Castilla y León (CIR\&CO) (T), y Encuentro de Unidades de Música (T).

Ciudad Vieja de Segovia y su Acueducto: I Jornadas de Turismo y Patrimonio Industrial (F/T), Domingos de Patrimonio 2015 (F/T), Presentación colección de monedas "Patrimonio de la Humanidad de España" (F/T), 30 Aniversario de la inscripción de la Ciudad Vieja de Segovia y su Acueducto en la Lista del Patrimonio Mundial de Unesco (F/T), Visita de agentes de viajes de China (F/T), II Competición Internacional de Esgrima "Ciudad de Segovia" (F/T), V Carrera Monumental (F/T), Fitur 2016 (F/T), Feria Madrid Fusión (F/T), II Jornadas de sensibilización sobre la cultura japonesa y necesidades del viajero japonés (F/T), Eventos culturales en la Casa de la Moneda (F/T), Conmemoración IV Centenario del fallecimiento de Miguel de Cervantes (F/T), Ciclo de Órgano de Primavera (F/T), Tren Antonio Machado (F/T), Visitas guiadas teatralizadas: "las Damas de Isabel" (verano), personaje arriero Claudio (F/T), XVII Jornada Europea de la Cultura Judía (F/T), Govigymkhana (F/T), Conmemoración Día de la Solidaridad de las Ciudades del Patrimonio Mundial: patrimonio y movilidad y Semana Europea de la movilidad (F/T), 11 Muestra de Cine europeo Ciudad de Segovia MUCES (F/T), $12^{\circ}$ concurso de OCPM "Navegando por las Ciudades Patrimonio Mundial de Europa del Sur/Mediterráneo" (F/T), I Jornadas Acueducto de Segovia (F/T), Día Mundial del Turismo (F/T), Jornadas Teresianas (F/T), II Encuentro Europeo de Asociaciones de Patrimonio Mundial en la Real Casa de Moneda de Segovia (F/T), I Reunión de Ciudades Romanas del valle del Duero (F/T), Paseo nocturno especial "Noche de ánimas" (F/T), Presentación oferta cultural Ciudades Patrimonio de la Humanidad (F), Ciclo Música en los Barrios (F), Charla sobre los primeros pobladores de nuestra ciudad (F), Acto de presentación del monográfico del Acueducto (F), Reunión de la Comisión de Patrimonio del Grupo de Ciudades Patrimonio de la Humanidad de España en la sede de la Casa Árabe en Madrid (F), Rodaje video promocional de la ciudad de Segovia (F), Conmemoración Día Internacional de los Monumentos y Sitios (F), Día de la Fundación de la ciudad romana: "El legado de Roma" (F), Visita alumnos del CEIP Carlos de Lecea Casa de la Moneda (F), Feria Nacional de Artesanía (F), Conmemoración Día Internacional de los archivos (F), Press trip (periodistas norteamericanos especialistas en viajes) (F), Visita grupo de actores de Bollywood (F), "Con ojos de poeta": clase sobre Antonio Machado (F), X Jornadas de Montaña de Segovia (T), Feria INTUR (T), Feria de cerámica y alfarería (T), Actos en conmemoración del aniversario la muerte de San Juan de la Cruz (T), Carrera de Fin de Año (T), $8^{\circ}$ Foro de Liderazgo Turístico de Exceltur (T), Asamblea de la Red de Ciudades AVE (T), Presentación del congreso de turismo y gastronomía (T), Actos en conmemoración 77 aniversario de muerte Antonio Machado (T), IX Ciclo de Actividades en la Judería de Segovia (T), 20 Aniversario Paladio Arte (T), Concurso de carteles del Grupo de Ciudades Patrimonio de la Humanidad de España (T), Simposium Internacional de Murallas, Ávila (T), Ciclo de Conferencias "La Ciudad Romana: Imagen e Ideología" (T), Promoción de las Ciudades Patrimonio de la Humanidad en América y Asia (T), Gymkhana del Patrimonio (T), Día internacional de los Museos (T), Festival de Música Diversa (T), $9^{\circ}$ Festival "Vete al Fresco" (T), Ciclo de "Música en el Jardín del Rey" (T), IV Feria del Jamón (T), VI Lecciones de Arte de la Real Academia de Historia y Arte de San Quirce en Segovia (T), Festival Internacional de Cortometrajes de Animación 3D Wire (T), Colección de títeres Francis Peralta (T), $2^{\circ}$ Aniversario de la apertura al público de la torre de la Catedral de Segovia, jornada de puertas abiertas (T), "Paralelo20": iniciativa cultural (T), "Machado al piano": Recital de poemas homenaje a A. Machado (T), y Concurso Tapas y Cócteles (T).

Ciudad Vieja de Santiago de Compostela: Navidad (F/T), Exposición de arte contemporáneo en la plaza del Obradoiro (F/T), Carrera nocturna SantYaGo10K (F/T), ITB de Berlín (F/T), Exposición Con-Fio en Galicia (F/T), Blogtrip (F/T), Fiestas de San Xóan (F/T), Festividad Santiago Apóstol (F/T), Expo "Picheleir@s" (F/T), XIII Edición Curtocircuíto - International Film Festival. (F/T), Jubileo de la Misericordia (F), Actuación de la tuna de la universidad de Méjico en la plaza del Obradoiro (F), VI Edición Cidade Imaxinaria (F), Concurso online mejor catedral de España (F), XXIX edición de Cineuropa_SCQ (T), Concursos gastronómicos: "Santiago de Tapas", "Santa tapas", "De tapa en tapa" (T), IBTM World (Barcelona) (T), Fitur 2016 (T), Holiday World Show (T), Carnaval (T), Jornadas de trabajo en Seúl (T), III Ciclo de Música de Cámara en las Ciudades Patrimonio de la Humanidad (T), "Programas de Lugares y Órganos" (T), Semana Santa (T), II Carrera Universitaria Solidaria (T), Exposición de fotógrafos en Compostela (T), Fiestas de la Ascensión (T), III Carrera 'Camiño das Letras' (T), Feria "Arte y San” (T), II Carrera y Caminata Solidarias por la Esclerosis Múltiple (T), "La revolución de los cuidados" (T), 
Semana Europea de la Movilidad (T), Jornada "Santiago Turismo Ordenado: Repensando a relación entre turismo e cidade" en Belvís (T), y ITB de Asia de Singapur (T).

Arquitectura mudéjar de Aragón: Eventos promocionales y plan de ferias 2016 por Europa, España y otros (F/T), XI Salón Aragonés del Turismo ARATUR (Zaragoza) (F/T), B Travel Show (F/T), Jornadas de Formación Turística (F/T), Campaña "Mudéjar abierto" (F/T), World Travel Market in London, WTM15 (T), Jornada para la creación y comercialización de experiencias turísticas Segittur (T), I Jornadas Turísticas en Aragón de la Escuela Universitaria de Turismo en Zaragoza (T), Jornadas Gastronómicas de Semana Santa, "Gastropasión" (T), Visita de periodistas de Marsella y París (T), Expovacaciones 2016 (T), Feria Mudéjar en Utebo (T), y Día Mundial del Turismo (T).

Ciudad Histórica de Toledo: $1^{\mathrm{er}}$ aniversario del Museo de Tapices de la Catedral Primada (F/T), Capitalidad Gastronómica: (F/T), Hanuká (F/T), Casting de la próxima edición de MasterChef (F/T), Feria del Dulce (F/T), Corpus (F/T), III ciclo de conciertos "Música de Cámara en las Ciudades Patrimonio de la Humanidad de España" (F/T), Día de los Museos: "Museo y Paisajes culturales" (F/T), Visitas personalidades públicas cine (F/T), Rodaje de película Bollywood (F/T), Visita de un grupo de jóvenes universitarios de Colorado: "En busca de las raíces judías" (F), Finisterra Arrábida Film Festival de Arte y Turismo de Sesimbra (Portugal) (F), Concurso en Facebook del Grupo de Ciudades Patrimonio de la Humanidad de España (F), Rodaje serie "La Catedral del Mar" (F), XVI Edición de las Jornadas de la tapa (T), Concurso en Twitter (T), Navidad (T), Fitur 2016 (T), Rodaje reality show de China (T), Semana Santa (T), Feria del Libro (T), y Feria de Artesania: Farcama (T)

Ciudad Vieja de Cáceres: Mercado Medieval de las Tres Culturas 2015 y 2016 (F), Navidad Cáceres 2015 (F), 30 Aniversario de la Declaración como Patrimonio de la Humanidad por la Unesco (F), Día de los guías turísticos (F), XXIII Festival Solidario de Cine Español de Cáceres (F), Festival de Cine de Turismo de la Feria ITB de Berlín (F), Casting para serie de época (F), Semana Santa (F), Rodaje película (F), Romería Patrona de Cáceres (F), XXV Rallye Turístico de Coches Antiguos, Ruta Cervantina y Tierra de Conquistadores (F), Festividad de San Jorge (Patrón) (F), WOMAD Cáceres 2016. 25 aniversario (F), Jornada técnica: Festival de las Aves en Cáceres (F), Día Internacional de los Museos (F), Feria de San Fernando de Cáceres 2016 (F), Festival de teatro clásico de Cáceres (F), XI Feria Extregusta (F), I Jornada sobre la función social del Patrimonio (F), XXI Edición Empresario Extremeño del año (F), Noches Solidarias del Baluarte (F), Rodaje serie Catedral del Mar (F), Jornada Europea de la Cultura Judía (F), Casting y rodaje serie Juego de tronos (F), Rodaje serie Still Star Crossed (F), Inauguración de la exposición "Laberintos Líricos" (F), y "Cáceres, vive tu patrimonio (F).

Catedral, Alcázar y Archivo de Indias de Sevilla: Rodaje serie Emerald City de la NBC (F/T), Visitas nocturnas teatralizadas (F/T), Ópera Carmen en el Real Alcázar de Sevilla (F/T), Visita personalidad política (F/T), Noches en los Jardines del Real Alcázar (F/T), Rodaje serie Juego de Tronos (F/T), Visitas solidarias al Alcázar de Sevilla (T), Encuentro Anual del Consorcio de agencias de viajes de EEUU y Canadá 'Ensemble' (T), ASTA Destination EXPO (T), Día Mundial del Turismo (T), y Rodaje serie The White Princess (T).

Monasterio de Poblet: Visita de periodistas alemanes (F), Conmemoración del 75 aniversario de la restauración de la comunidad cisterciense (F), Reunión de la comisión para la promoción del turismo en la Cuenca de Barberá (F), Programa "25 propuestas": ruta con juego detectivesco (F), Visita de personalidad pública (deportes) (F), Mercado de escapadas de Barcelona (F), Caminatas populares: naturaleza y patrimonio (F), Festival de música Antigua de Poblet (F), Visita de periodistas de la TV francesa, TF1 (F), Visita de periodistas de la TV pública alemana del estado de Hessen (F), Stands informativos y promocionales en el Festival de Playmobil de Montblanc (Conca de Barberá): Clickània (F), IV Festival internacional órganos de aldea (F), Presentación revista turística descobrir.cat (F), y Concierto de órgano de Juan de la Rubia en el Monasterio (T).

El Camino de Santiago: V Foro Consultivo de Itinerarios Culturales Europeos del Consejo de Europa (F/T), Presentación online de "Xacopedia (F/T), Exposición "Silencio, el monacato en el Camino" (F/T), Exposición itinerante "Acogida y hospitalidad en el Camino de Santiago" (F/T), Año jubilar de la Misericordia (F/T), Premios Camino de Santiago 2015 y 2016 (F/T), Foro de empresas de la Asociación de Municipios del Camino de Santiago en Jaca (F/T), Fitur 2016 (F/T), Semana de puertas abiertas y visitas guiadas en el Pazo de Xelmírez en Santiago (F/T), Realización del camino por personajes públicos, populares, etc. (F/T), Jornadas internacionales Misericordia y Peregrinación (F/T), IV edición de "Cultura en el Camino" (F/T), Vuelo del Botafumeiro (F/T), "Vive o Camiño 2016 (F/T), Fiestas del Apóstol Santiago (F/T), Proyección del documental Walking the Camino (F/T), Exposición de fotografía "Via Lacobitana I" "Via Lacobitana II" (F/T), Traslación de Santiago (F), Presentación documental Terry Porter, "el Camino acaba en Obradoiro" (F), Peregrinación por el Camino del Norte (F), Exposición "Galicia, Casa 
de los Peregrinos" (F), Vuelta ciclista a España (F), Visitante/peregrino n ${ }^{\circ} 200.000$ (F/T), Exposición "A la luz del Calixtino. El Códice de Santiago" (F/T), X Jornadas en Defensa de los Caminos Públicos (F/T), Conferencia "Galicia y los Caminos de Santiago" (F/T), Conferencia "El relato de peregrinación de Gian Lorenzo Buonafade Vanti (1717) y su paso por Monforte y la Ribeira Sacra (F/T), Día Mundial de la sonrisa (F), Entrega oficial del título de Embajador de Honor del Camino a Vicente del Bosque (F/T), "Footprints, el camino de tu vida" (F/T), Jornadas del programa de profesionalización en el Camino (T), y VIII Concurso de Fotografía Vía da Prata (T).

Monasterio Real de Santa María de Guadalupe: Recital de música tradicional (F/T), I Marcha Cicloturista Solidaria (F/T), Mercado de productos ecológicos (F), Día de la Hispanidad (T), y IV Mercado Artesanal en Guadalupe (T).

Conjunto arqueológico de Mérida: Capital iberoamericana de la cultura gastronómica 2016 (F), Conmemoración Día Internacional contra la Violencia de Género (F), Día Internacional del Voluntariado (F), Visitas guiadas nocturnas al Teatro-Anfiteatro (F), V diploma Mérida Patrimonio de la Humanidad memorial Manuel Domínguez, de la sección local de la Unión de Radioaficionados de España (F), San Valentín (F), Seminarios de Patrimonio Mérida, arqueología e historia (F), II Ciclo de música de cámara Grupo Ciudades Patrimonio (F), Conmemoración Día internacional de la Mujer (F), Evento de recreación de un Castra del Ejército romano (F), X Media Maratón Mérida "Patrimonio de la Humanidad" (F), Semana Santa (F), Concurso en Facebook del Grupo de Ciudades Patrimonio de la Humanidad de España (F), Feria lBT Berlín (F), Reunión de la Comisión de patrimonio del Grupo de Ciudades Patrimonio de la Humanidad de España (F), II Rally de fotografía (F), Programa "20 años, 20 Monumentos" (F), Programa 'Aula Patrimonio' del Grupo de Ciudades Patrimonio de la Humanidad de España (F), Concurso diseño del cartel sobre la necesidad de protección del medio ambiente en los cascos históricos de las 15 ciudades que forman El Grupo de Ciudades Patrimonio de la Humanidad de España (F), IV edición del Desafío por la Salud (F), Visita a Mérida de miembros de la asociación defensora del Patrimonio Histórico Hispania Nostra (F), Visita con fines solidarios: de los Padrinos de Bodouakro (F), XX Edición del Festival internacional de Teatro Juvenil Grecolatino (F), 62 edición Festival Internacional de Teatro Clásico de Mérida (F), XX Aniversario, el Consorcio: jornada académica y de convivencia (F), Programa "La escuela adopta un monumento" (F), VII Emerita Lvdica (F), Conmemoración Día Internacional de la Danza (F), Conmemoración del Dos de Mayo y del 50 aniversario del grupo de artillería XI (F), Concierto de presentación de la Joven orquesta Ciudad de Mérida (F), I Jornada Nacional de Sexología (F), Acto de promoción de la oferta turística de las Ciudades Patrimonio de la Humanidad de España en Lisboa (F), Reunión de la Comisión de Educación y Cultura del Grupo de Ciudades Patrimonio de la Humanidad de España (F), Asamblea general del Grupo Ciudades Patrimonio de la Humanidad de España (F), Homenaje a las víctimas del atentado de Orlando (F), Presentaciones técnicas en Seúl, Tokio y Manila (F), Presentación de las 15 ciudades del Grupo de Ciudades Patrimonio en Málaga para turoperadores (F), I Jornadas sobre "La Función Social del Patrimonio" (F), Presentaciones técnicas en Canadá del Grupo de Ciudades Patrimonio (F), Exposición Temporal: Theatrvm (F), Inauguración de la exposición Theatrvm en el Museo Nacional de Arte Romano (F), Campeonato de España de Ciclismo Escolar (F), Grabación en directo programa radiofónico "No es un día cualquiera" de RNE (F), XIV Edición" Los jueves del Museo" (F), Stone \& Music Festival (F), 30 edición Festival Folklórico de los Pueblos del Mundo (F), Talleres infantiles del museo sobre grandes mitos de la cultura clásica (F), Presentación nuevo curso 2016/17 de la Escuela de Teatro de Taptc (F), Conmoración Día del Museo: encuentro "Pensando y Haciendo Museos" (F), XXX Aniversario del MNAR (F), Presentación exposición "Laberintos Líricos" (F), Día de Extremadura (F), I Carrera Popular Solidaria e Inclusiva \#HeroeSSincapa (F), Día de la Ruta Vía de la Plata (F), Visita turoperadores de Miami (F), Feria JATA de Tokio 2016 (F), Día del Turismo (F), Reunión de la Comisión de Patrimonio del Grupo de Ciudades Patrimonio de la Humanidad de España (F), Exposición-Recreación "Juego de espejos" (F), III Festival Ibérico de Teatro Amateur (F), Feria Chica de Mérida (F), Ciclo de conferencias mensuales sobre el mundo Romano "Emerita Antiqua" (F), Presentación de la oferta cultural y turística del Grupo Ciudades Patrimonio de la Humanidad en el Instituto Cervantes de Budapest (F), Grabación en directo programa radiofónico (F), Recreación de la celebración fin del fin de las Campañas Bélicas, el Armilustrium (F), Presentación de las 15 Ciudades Patrimonio de la Humanidad de España, en la sede de la ONU en Ginebra (F), y Campaña Educativa de Otoño del MNAR. Taller: "Dos túnicas y un manto" (F).

Ciudad Histórica amurallada de Cuenca: Fitur 2016 (F), 20 Aniversario de su inclusión en la Lista del Patrimonio Mundial (F), 55 Edición de la Semana de Música Religiosa (F), Semana Santa (F), Feria del libro de Cuenca (F), Rodaje reportaje Cuenca por la productora japonesa TBS Vision (F), Visita de representantes de agencias de viajes Mejicanas (F), Visita de personal de la Oficina Municipal de Turismo a la Exposición del artista chino Ai Wei Wei (F), I Jornadas del Misterio Ciudad de Cuenca 
2016 (F), Representación "La conquista de la ciudad por el Rey Alfonso VIII de Castilla" y mercado medieval, (F), Video mapping en la fachada de la Catedral de Cuenca (F), Inauguración órgano gótico y carrillón de campanas medievales (F), y III Jornadas de teatro español de títeres (F).

La Lonja de la Seda de Valencia: Día Internacional de los Monumentos y Sitios (F/T), Día internacional de los Museos (F/T), Día de la Comunidad Valenciana (F/T), Congreso Internacional sobre la seda (T), y Visita teatralizada barrio Velluters (T).

Las Médulas: Feria INTUR Valladolid (F/T), $18^{\circ}$ aniversario de la Declaración del paraje como Patrimonio de la Humanidad (F/T), Fitur 2016 (F/T), Visita de Responsables del Consejo Comarcal del Bierzo a Escucha (F/T), y Exposición de los coches clásicos del Rally "Terras do Incio" (F).

Palau de la Música Catalana y Hospital de Sant Pau: Conciertos de Músicas del Mundo en los jardines del recinto modernista Sant Pau (F/T), y Programación Palau de la Música (T).

Universidad y recinto histórico de Alcalá de Henares: Tren de Cervantes (T), Exposición "Miguel en Cervantes (T), Premios Cervantes 2015 (T), "Las Noches de Don Juan" (T), Exposición 500 años de la Magistral de Cisneros (T), Concurso Otoño en las Ciudades Patrimonio de la Humanidad (T), IV Centenario de la Muerte de Cervantes (T), XVII Aniversario de su declaración como Patrimonio Mundial: (T), Encuentro de Técnicos de Turismo del Grupo de Ciudades Patrimonio de la Humanidad (T), Fitur 2016 (T), Visita promocional de Rodolfo Sancho (T), Carnaval (T), XXX Semana Gastronómica (T), Ruta de los vinos de Madrid (T), Fiesta de la Música (T), 16 Festival de Teatro "Clásicos" (T), Visita de Carolina Marín (T), Visitas Guiadas a las obras del Monasterio de las Bernardas "Abierto por Obras" (T), Visita de periodistas de Ensemble Travel Group (T), Visita nocturna a las Murallas de Alcalá y antiquarium del Palacio Arzobispal (T), Conciertos de la Muralla (T), Día Mundial del Turismo (T), Visitas Guiadas y teatralizadas gratuitas "Historias de Complutum" (T), y XXXII Representación del Don Juan en el recinto amurallado del Palacio Arzobispal (T)

San Cristóbal de la Laguna: $7^{\mathrm{a}}$ "Noche en Blanco" (F/T), XVI Aniversario de declaración de La Laguna como Patrimonio de la Humanidad por la Unesco (F/T), Concurso de fotografía Ciudades Patrimonio: "Otoño en las ciudades patrimonio" (F/T), Exposición "San Cristóbal de La Laguna. Patrimonio Mundial” (F/T), Fitur 2016 (F/T), Reunión en Madrid de la Comisión de Turismo del Grupo de Ciudades Patrimonio de la Humanidad de España (F/T), Resumen Shower Festival 2015 (F/T), Ruta cultural en bici (F/T), ITB de Berlín (F/T), Salón Internacional de Turismo de París (F/T), III Foro de Turismo en Canarias, Futurismo 2016 (F/T), XXVI Congreso de la Sociedad Canaria de Medicina Familiar y Comunitaria (F/T), Visita 120 agentes de viajes de Globalia-Travelplan (F/T), Promoción de las Ciudades Patrimonio de la Humanidad de España en América y Asia (F/T), IV Semana Internacional de Jazz Ciudad de La Laguna 2016 (F/T), Promoción en Portugal junto al Grupo de Ciudades Patrimonio de la Humanidad de España y visita de equipo de la Televisión Portuguesa (F/T), "Diablos y Tarasca"(F/T), Fiesta de la Música de La Laguna 2016 (F/T), Nueva edición de "La Laguna Encuentro con África" (F/T), Presentación campaña "La Laguna tiene una historia que contarte" en Seatrade Cruise Med (F/T), Conmemoración Día Internacional del Turismo 2016 (F/T), $8^{\text {a }}$ Noche en Blanco (F/T), Rodaje videoclip de Jairo Martín (F), Concurso en RRSS Grupo de Ciudades Patrimonio de la Humanidad de España (F), Asistencia a la Asamblea General del Grupo Ciudades Patrimonio de la Humanidad de España (F), Congreso Internacional de Turismo (F), Concierto en el Antiguo Convento de Santo Domingo (F), Exposición fotográfica "Ciudades Patrimonio de la Humanidad. 15 Joyas de España" en el Instituto Cervantes de Hamburgo (F), Presentación en el Museo Thyssen-Bornemisza de Madrid de la oferta turística y cultural de las ciudades pertenecientes a Grupo de Ciudades Patrimonio de la Humanidad de España (F), Ruta de los Conventos (F), Ciclo "Jazz en el Convento" (F), Visita de directivos y gerentes de la empresa City Sightseeing (F), II Festival Internacional Benéfico de Música en solidaridad con Nepal (F), II Conferencia Autonómica de Participación Ciudadana (F), Semana Santa (T), II Edición Shower Hidrosfera Festival (T), Presentación de "Los amantes de Verona visitan La Laguna” (T), IV Festival Internacional Latino La laguna 2016 (T), Ciclo de Música de Cámara de las Ciudades Patrimonio de la Humanidad (T), Presentación del Encuentro de Cultura y Derechos Humanos La laguna 2016 (T), 9 a edición de la Ruta de la Tapa por San Benito (T), Sunsets Summer Sessions (T), $3{ }^{\text {er }}$ Festival "La Laguna descubriendo Tangos" (T), I Paseo Canino San Cristóbal de La Laguna (T), Semana Europea de la Movilidad (T), III Congreso Iberoamericano de Innovación Pública "Personas, valores y tecnología" (T), Festival "Musicando Alegría · Movimento Santuka" 2016 (T), y II Festival Internacional Benéfico de Música en solidaridad con Nepal (T).

Conjunto arqueológico de Tárraco: 15 Aniversario de la Declaración de Tárraco como Patrimonio mundial (F/T), Visita teatralizada "Habitantes de Tárraco" (F/T), Asistencia a Feria de Utrecht (F/T), Asistencia a Feria de Bruselas (F/T), Presentaciones de producto junto a Grupo Ciudades Patrimonio de la Humanidad en mercado asiático (F/T), Rodaje serie 4K “Ciudades Españolas Patrimonio de la Humanidad” 
de RTVE (F/T), Exposición "La moneda en época de Augusto" (F/T), Festival “Tárraco Viva” (F/T), Programa de Talleres infantiles: "Al taller de Terenci Càndid" y teatro "Perseu, el Sant Jordi grec" (F/T), Programa "Tarragona Family Week" (F/T), Eclèctic Festival (F/T), Programa "ViTour Tarragona" (F/T), Concierto de Los Ludi Scaenici (F/T), Conmemoración Día Mundial del medioambiente (F/T), Asistencia a Congreso AST Sevilla (F/T), Festival de Danza (F/T), Programa "Tarragona Historia Viva" (F/T), Concurso Internacional de Fuegos artificiales Ciutat de Tarragona, y $7^{\mathrm{a}}$ edición "Sopars sota els focs" (F/T), Festival de verano (F/T), Ciclo "Una semana con Historia... en el MNAT" (F/T), Santa Tecla 2016 (F/T), Día del Turismo (F/T), Acto de presentación de la oferta turística y cultural de las ciudades del Grupo de Ciudades Patrimonio de la Humanidad de España en el Museo Thyssen-Bornemisza de Madrid (F/T), Celebración de las fiestas de Sant Martí (F), Asistencia a Feria Reisen de Hamburgo (Alemania) (F), Día Internacional de la Mujer (F), Fotógrafo invitado (F), Presentación del audiovisual "La Tárraco de los primeros cristianos" (F), "Vacaciones en Tárraco" (F), Concierto dúo de guitarra y flauta travesera (F), Hispania nuestra. 40 Aniversario (F), II FoodTruck Festival \& Vintage Market (T), Exposición "Foto del día" (T), 22 Festival Internacional de Dixieland de Tarragona. (T), Tarragona de Tapes (T), Sant Jordi (T), Exposición "Redescubriendo Centcelles" (T), Festival Escena en la Villa Romana de Altafulla (T), 8 edición de La Imaginada (T), Fiestas de San Roque (T), Famtrip de periodistas de Miami (T), y Festival de fotografía: exposición Talent Latent (T).

Iglesias románicas catalanas del Vall de Boí: Rodaje y emisión del rodaje del Programa TV Cafeïna Tour (F/T), FeMAP - Festival de Música Antiga (F/T), Presentación Alta Ribagorça en Barcelona (F/T), Visita del presentador y rodaje programa TV: elforastertv3 (F/T), Concurso online "Monumento favorito de Cataluña" (F/T), Visitas de prensa mejicana "Catalunya Románica" (F/T), Treckfestival (F/T), Visitas de prensa, y medios de comunicación (F/T), "Romànic a escena" (F/T), 25 años de "Dijous a la fresca" (F/T), $4^{a}$ edición "La noche de la luz (F/T), Fira de Barruera (F/T), Rodaje de programa Divendres de TV3 "En Patrimonio" (F), Jornadas Europeas del patrimonio en la Vall de Boi (F), "Caminem pel Romànic" (F), Navidad (T), Asistencia a Mercado de escapadas de Barcelona (T), Visita de los blogueros de turismefacil. org (T), Fiesta de la "guinsa" (T), Sesiones de trabajo en la Vall de Boi con empresarios del sector turístico (T), 22 edición de las Jornadas gastronómicas del boletus (T), y Asistencia a Fires Girona (T)

Palmeral de Elche: Jornadas de puertas abiertas (F/T), XV Aniversario de la Declaración del Palmeral de Elche Patrimonio de la Humanidad por la Unesco (F/T), Conciertos en el Parque Municipal (F/T), Congreso Eurotoques 2016 (F/T), Día Internacional de los Museos (F/T), Ruta de iniciación a la marcha nórdica (F/T), Festival de cine de Elche (Palmeral) (F/T), X Àgora Heliketana (F/T), Campeonato Internacional de Trepa de Palmera "Palmeral de Elche" (F/T), Famtrip: jornada para profesionales sector turístico Red Tourist info Comunitat Valenciana (F/T), Fireta del Camp d’Elx (F/T), Halloween en el Palmeral (F/T), Navidad: concierto en el parque municipal (T), Exposición de bonsais en la rotonda del Parque Municipal (T), y Día mundial del Turismo (T).

Muralla romana de Lugo: XXV Festival de Jazz de Lugo (F/T), XV Aniversario de la Declaración de la Muralla Romana de Lugo como patrimonio de la Humanidad (F/T), XIII Carrera Lugo Monumental (F/T), Cabalgata de Reyes Magos (F/T), Vuelta ciclista a España: Lugo punto de llegada (F/T), Presentación institucional candidatura "Muramiñae: da muralla ao Miño" (F/T), Fitur 2016 (F/T), XVI Muestra de teatro clásico (F/T), Día Internacional de la Mujer (F/T), Seminario sobre las tecnologías de la información y la comunicación para la difusión de ciudades históricas en Florencia y presentación proyecto "Muralla digital" (F/T), Lvevs Cultural (F/T), Día Mundial del Autismo (F/T), Ruta "Os cazadores de minerais" (F/T), MMXVI Arde Lvcvs 2016 (F/T), Asistencia a Congreso Internacional de Murallas del Grupo de Ciudades Patrimonio de la Humanidad (F/T), XXVIII Triatlón do Miño (F/T), "Volta Junior" (F/T), Acto solidario pro enfermedades raras (F/T), Ruta "Terras de auga e cultura" (F/T), Día Internacional de los museos (F), y IX Desafio Volta a Lugo (T).

Conjunto monumental renacentista de Úbeda y Baeza: XVIII Festival de Música y Danza Ciudad de Úbeda (F/T), XVIII Certamen Nacional de Tunas "Andrés de Vandelvira" (F/T), Fitur 2016 (F/T), Semana Machadiana (F/T), Semana Santa (F/T), VII Jornadas de Ciencia para tod@s (F/T), Úbeda y Baeza 10 / Experiencias 10 (F/T), Concurso "Baeza, conoce su Patrimonio" (F/T), XIII Fiestas del Renacimiento (F/T), XIII Aniversario de la Declaración de Úbeda y Baeza Patrimonio de la Humanidad por la Unesco Música (F/T), Visita de periodistas chinos para reportaje (F), Día de los Museos (F), Seminario "Reputación on-line y mejora de prestigio en el sector turístico" (F), Navidad en Úbeda (T), XV Jornadas gastronómicas en el Renacimiento (T), Carnaval de Úbeda (T), Día Internacional de la Mujer (T), Concurso para elegir cartel sobre protección medioambiental organizado por el Grupo de Ciudades Patrimonio de la Humanidad (T), Día Internacional de los Monumentos y Sitios de la Unesco (T), III Ciclo Música de Cámara en las Ciudades Patrimonio de la Humanidad de España (T), Día Mundial de Star Wars en Úbeda (T), XIII Semana Santa Chica de Úbeda (T), Sábados de Ciencia y observación 
solar (T), XVII Encuentro nacional de encajeras en Úbeda (T), $3^{\text {as }}$ Jornadas y Concurso "Sabina por aquí" (T), Día de la Patrona de Úbeda - 75 Aniversario nombramiento Alcaldesa Perpetua de la ciudad de Úbeda (1941-2016) (T), $12^{\circ}$ Concurso de Internet "Navegando por las Ciudades Patrimonio Mundial de la OCPM" 2016 (T), Feria y fiestas de San Miguel de Úbeda (T), Día mundial del Turismo (T), y $4^{\circ}$ Concurso Juvenil de Fotografía de las Ciudades Patrimonio Mundial de la Humanidad (T).

El Puente de Vizcaya: Getxo Feria de artesanía (F/T), Festival cultural Smithsonian Folklife Festival: (F/T), III Trofeo Internacional Ciudad de Getxo de Patinaje Artístico (F/T), Mes de los museos de la Costa Vasca (F/T), Visita interactiva "Paseo de las Grandes Villas" (F/T), Jornada de trabajo de la Red de Ciudades Interculturales, RECI (F/T), Día Mundial de los Monumentos y Sitios (F/T), Recorridos toponímicos (Getxo) (F/T), Festival "Ken Zazpi" (F/T), III Getxo Skating Race (F/T), Festival Internacional de Jazz de Getxo (F/T), Europride 2016 Amsterdam (F/T), y Entrada libre y actividades especiales en los museos de la costa vasca tras Semana Santa (T).

Torre de Hércules: Visitas guiadas y teatralizadas gratuitas con personajes prescriptores: Mil Espane, nieto de Breogán y Catuxa (F/T), Carnaval (F/T), Concurso mundial de fotografía de la Unesco en Instagram (F/T), San Patricio (F/T), Concurso "Expontáneas" (F/T), Día Mundial de la concienciación sobre el Autismo (F/T), Visita gratuita 25 de abril (F/T), $7^{\circ}$ aniversario de la inscripción de la Torre de Hércules en la lista de Patrimonio Mundial de la Unesco (F/T), Visita touroperadores alemanes (F/T), Presentación del World Padel Tour (WPT) (F/T), Día del Daño Cerebral Adquirido (F/T), Día Mundial de las Enfermedades Raras (F), Día de la Concienciación de la Sarcoidosis (F), Día Mundial del Lupus (F), Exposición virtual de la evolución de Acoruña en el siglo XX (F), Observación de lluvia de estrellas (F), Día Mundial de la Diabetes (T), Fitur 2016 (T), VIII edición de la Media Maratón Coruña 21 (T), Día Internacional de la Mujer (T), Día Mundial de los Monumentos y Sitios (T), Día Internacional de los Museos (T), Día Mundial del Alzheimer (T), Visita bloguero italiano (T), y Día Mundial de la Parálisis Cerebral (T).

Paisaje cultural de la Sierra de la Tramontana: Gastrotast-2016 (F/T), Fira de la Mar y Trobada de Havaneres (F/T), y Feria de Antigüedades y Coleccionismo de la Serra de Tramontana (F/T).

Dólmenes de Antequera: Día Internacional del Patrimonio Mundial (F/T), Sesiones de yoga y chikung (F/T), Celebraciones del sol en el equinoccio de invierno, primavera y otoño (F/T), Fitur 2016 (F/T), Conferencia sobre el Sitio de los Dólmenes en la Sociedad Económica de Amigos del País (F/T), Carnaval (F/T), Conciertos en apoyo a los Dólmenes (F/T), I Vespepe "Ciudad de Antequera" (F/T), Jornadas Técnicas Municipales sobre el expediente de Dólmenes ATQ_WH (F/T), Día Internacional de los Monumentos y Sitios (F/T), Semana de Antequera en Málaga (F/T), Día de la Provincia (F/T), Día Internacional del Museo (F/T), Concierto Orquesta Sinfónica Provincial de Málaga (F/T), Festival gastronómico Food Truck (F/T), Retransmisión en directo de la probable declaración de Dólmenes ATQ_WH como Patrimonio Mundial de la Unesco (F/T), Espectáculo de luces para celebrar la Declaración de los Dólmenes como Patrimonio Mundial del Sitio (F/T), Café de trabajo por visita grupo de touroperadores (F/T), I Media Maratón BTT "Antequera, Patrimonio Mundial” (F/T), ITB Berlín (T), Programa "Luz de luna - Moonlight 2016" (T), Feria de Agosto (T), y Promoción en las jornadas de turismo cultural y gastronómico de EE.UU y Canadá (T).

\section{Bibliografía}

Área de Patrimonio Cultural del Ministerio de Educación, Cultura y Deporte

2017. Recuperado el 01/03/2017, de: http://www.mecd.gob.es/cultura-mecd/areas-cultura/patrimonio/ $\mathrm{mc} /$ patrimoniomundial/bienes-declarados/por-tipo-de-bien.html

Batthyány, K. \& Cabrera, M.

2011. Metodología de la investigación en Ciencias Sociales. Apuntes para un curso inicial. Montevideo: Universidad de la República.

Bigné, J. E., Font, X., \& Andreu, L.

2000. Marketing de destinos turísticos: Análisis y estrategias de desarrollo. Madrid: Esic editorial. Campillo, C.

2012. El desarrollo de políticas estratégicas turísticas a través de la marca acontecimiento en el municipio

de Elche (2000-2010). Pasos, Revista de Turismo y Patrimonio Cultural, 10 (1), 119-129.

Campillo, C., Ramos, I. \& Castelló, A.

2014. La gestión estratégica de la marca en los eventos empresariales 2.0. AdResearch, 10 (10), 52-73. Caro, J.L., Luque A. \& Zayas B.

2015. Nuevas tecnologías para la interpretación y promoción de los recursos turísticos culturales. Pasos, Revista de Turismo y Patrimonio cultural, 13(4), 931-945. 
De la Calle Vaquero, M.

2002. La ciudad histórica como destino turístico. Barcelona: Ariel.

Domínguez, T. \& Araujo, N.

2012. El fenómeno 2.0 en el sector turístico. El caso de Madrid 2.0. Pasos, Revista de Turismo y Patrimonio Cultural, 10 (3), 225-237.

Ejarque, J.

2005. Destinos turísticos de éxito: Diseño, creación, gestión y marketing. Madrid: Pirámide.

Ejarque, J.

2016. Marketing y gestión de destinos turísticos: Nuevos modelos y estrategias 2.0. Madrid: Pirámide.

Event Marketing Institute and FreemanXP

2015. Recuperado el 14 de septiembre de 2016. The Viral Impact of Events. Extending \& Amplifying Event Reach via Social Media, de: http://www.slideshare net/TCAnalysis/4-oleada-observatorio-de-redes-sociales

Fernández Vazquez, J., López Rodríguez, C. \& Arévalo Iglesias, L.

2016. Turismo cultural y nuevas tecnologías de la información: El caso del Camino de Santiago y el fomento de la marca país. Question, Revista Especializada en Periodismo y Comunicación 1 (49), 241-251.

Folgado Fernández, J. A.

2014. Influencia de la marca de los eventos en la formación de la imagen del destino turístico: Una contribución a la explicación de la fidelidad Recuperado el 10/10/2017, en: http://hdl.handle.net/10662/1359 González, Y.

2016. Un destino turístico no se tiene que promocionar, se tiene que promocomercializar. Recuperado el 12/07/2017, en: http://yeraygonzalez.es/como-promocionar-destino-turistico/

Hays, S., Page, S. J. \& Buhalis, D.

2013. Social media as a destination marketing tool: its use by national tourism organisations. Current Issues in Tourism, 16(3), 211-239.

Huertas-Roig, A.

2008. Aplicación de la Web 2.0 a los destinos turísticos. Implantación y diferencias. En: Guevara Plaza. A, Caro Herrero, J.L. \& Aguayo Maldonado, A. (Eds.). VII Congreso Nacional de Turismo y Tecnologías de la Información y las Comunicaciones. Turitec 2008, 268-283. Málaga: Universidad de Málaga, Escuela Universitaria de Turismo.

Huertas-Roig, A.

2014. La comunicación de los territorios, los destinos y sus marcas. Barcelona: UOC.

Huertas-Roig, A., Setó-Pàmies, D. \& Míguez-González, M.I.

2015. Comunicación de destinos turísticos a través de los medios sociales. El profesional de la información, enero-febrero, 24 (1), 15-21. //ddoi.org/10.3145/epi.2015.ene.02

Jiménez Morales, M. \& de San Eugenio Vela, J.

2009a. Identidad territorial y promoción turística: la organización de eventos como estrategia de creación, consolidación y difusión de la imagen de marca del territorio. ZER Revista de Estudios de Comunicación, 26, 277-297. Recuperado el 14 de septiembre de 2016, en: http://www.ehu.eus/zer/ es/hemeroteca/articulo/identidad-territorial-y-promocin-tursticala-organizacin-de-eventos-como-estrategiade-creacin-consolidacin-y-difusinde-la-imagen-de-marca-del-territorio/393.

Jiménez Morales, M. \& de San Eugenio Vela, J.

2009b. La organización de eventos como estrategia identitaria y evocadora de imagen turística. Estudio de caso: Girona Temps de Flors. Pasos, Revista de Turismo y Patrimonio Cultural, 7 (1), 73-84.

Laguna García, M.

2005. La celebración de eventos culturales como atractivo turístico en las ciudades históricas: Análisis del impacto económico y turístico. Estudios Turísticos, 166, 65-95.

Lara de Vicente, F. \& López-Guzmán Guzmán, T. J.

2004. El turismo como motor de desarrollo económico en ciudades patrimonio de la humanidad. Pasos, Revista de Turismo y Patrimonio Cultural, 2 (2), 243-256.

Mariani, M.M., Di Felice, M. \& Mura, M.

2016. Facebook as a destination marketing tool: Evidence from Italian regional Destination Management Organizations. Tourism Management, 54, 321-343.

Marine-Roig, E., \& Clavé, S. A.

2015. Tourism analytics with massive user-generated content: A case study of Barcelona. Journal of Destination Marketing \& Management, 4(3), 162-172. 
Marine-Roig, E., Martin-Fuentes, E., \& Daries-Ramon, N.

2017. User-Generated Social Media Events in Tourism. Sustainability, 9(12), 2250.

Márquez-González, C. \& Caro-Herrero, J.L.

2017. Ciudades Patrimonio de la Humanidad de España: la reputación online como elemento de desarrollo turístico. Pasos, Revista de Turismo y Patrimonio Cultural, 15 (2), 437-457.

Martínez-Sala, A. M.

2015. Calidad de websites turísticas oficiales de la costa mediterránea española (2004-2015). Tesis doctoral Universidad Miguel Hernández.

Martínez-Sala, A.M., Monserrat-Gauchi, J. \& Campillo-Alhama, C.

2017. El paradigma relacional en las estrategias de las organizaciones de marketing de destinos. Interactividad y función social en las webs turísticas oficiales. Revista Latina de Comunicación Social, 72, 374-396.

Martos Molina, M.

2013. Las ciudades patrimoniales en el mercado turístico cultural. Úbeda y Baeza. Pasos, Revista de Turismo y Patrimonio Cultural, 11 (1), 57-71.

Okech, R.

2010. Socio-cultural impacts of tourism on world heritage sites Communities perspective of lamu kenya and Zanzibar Islands. Asia Pacific Journal of Tourism Research, 15 (3), 339-351.

Pantano, E., Servidio, R. \& Viassone, M.

2011. An exploratory study of the tourist-computer interaction: the role of web site usability on hotel quality perception. International Journal of Digital Content Technology and its Applications, 5 (5): 208-216.

Pérez, J.A.

2006. Flujo turístico y repercusión económica en las ciudades patrimoniales. Ars et sapientia, 21, 47-60.

Pulido Fernández, J. I., \& López Sánchez, Y.

2013. Propuesta de contenidos para una política turística sostenible en España. Pasos, Revista de Turismo y Patrimonio Cultural, 11 (4), 525-546.

Ruiz Lanuza, A. \& Pulido Fernández, J. I.

2015. El impacto del turismo en los sitios Patrimonio de la Humanidad. Una revisión de las publicaciones científicas de la base de datos Scopus. Pasos, Revista de Turismo y Patrimonio Cultural, 13 (5), 1247-1264.

Santana Talavera, A.

2003. Turismo cultural, culturas turísticas. Horizontes Antropológicos, 9 (20), 31-57.

Santana Talavera, A.

2008. El turismo cultural: ¿un negocio responsable?. Estudios y Perspectivas en Turismo, 17 (4). Recuperado el 16/07/2016 de: http://www.scielo.org.ar/scielo.php?script=sci_arttext\&pid=S185 $1-17322008000400001$

Sigala, M.

2009. Web 2.0, social marketing strategies and distribution channels for city destinations: enhancing the participatory role of travelers and exploiting their collective intelligence. En: Gascó-Hernández, M. \&Torres-Coronas, T. Information communication technologies and city marketing. Digital opportunities for cities around the world. Hershey: Information Science Reference.

TURESPAÑA. Plan del Turismo Español Horizonte 2020.

2017. Recuperado el 16/07/2017, de: http://www.tourspain.es/es-es/VDE/Documentos\%20Vision\%20 Destino\%20Espaa/Plan_Turismo_Espa\%C3\%B1ol_Horizonte_2020.pdf

Troitiño Vinuesa, M. A.

2000. Turismo y ciudades históricas: retos y oportunidades. Turismo y Patrimonio, 1/2000, 27-34.

Troitiño Vinuesa, M. A.

2003. Ciudades históricas y turismo sostenible. A distancia, 1, 47-51.

Troitiño Vinuesa, M. A. \& Troitiño Torralba, L.

2012. Turismo y patrimonio en Castilla y León: Las ciudades patrimonio de la humanidad (Ávila, Salamanca y Segovia) como destinos turísticos de referencia. Polígonos. Revista de Geografía, 19, 145-178.

UNESCO

2004. La UNESCO y el Patrimonio Mundial. Bilbao: UNESCO ETXEA. Recuperado el 16 de julio de/2016, en: http://www.unescoetxea.org/dokumentuak/UNESCOPatrimonio.pdf 


\section{UNESCO}

2016. Lista del Patrimonio Mundial. Recuperado el 16 de julio de 2016, en: http://portal.unesco.org/es/ ev.phpURL_ID=45692\&URL_DO=DO_TOPIC\&URL_SECTION=201.html

\section{UNWTO}

2016. Annual report 2015. Recuperado el 1 marzo de 2017, en: http://cf.cdn.unwto.org/sites/all/files/pdf/ annual_report_2015_lr.pdf.

\section{UNWTO}

2015. Annual report 2014. Recuperado el 1 marzo de 2017, en: http://www2.unwto.org/annualreport2014 Velasco, M.

2009. Gestión turística del patrimonio cultural: enfoques para un desarrollo sostenible del turismo cultural. Cuadernos de Turismo, 23, 237- 253.

Wang, T. \& Zan, L.

2011. Management and presentation of Chinese sites for UNESCO World Heritage List (UWHL). Facilities, 29 (7/8), 313-325.

Xiang, Z. \& Gretzel, U.

2010. Role of social media in online travel information search. Tourism Management, 31, 179-188.

Xing Events

2014. Social Media \& Event Report. Disponible en: https://en.xing-events.com/fileadmin/user_upload/ Infomaterial/XINGEVENTS_SMR_EN_low.pdf

Yang, X.

2017. Industrial heritage tourism development and city image reconstruction in Chinese traditional industrial cities: a web content analysis. Journal of Heritage Tourism, 12(3), 267-280.

\section{Notas}

1 Santana-Talavera (2003: 2) justifica la utilización del patrimonio como valor cultural y turístico al afirmar que: "la conciencia colectiva, los intereses macro-económicos y la mirada de los grandes planificadores sociales, aunque con motivaciones diferenciadas convergieron en territorios y rasgos que años antes fueron bien abandonados a su suerte, bien no considerados como recurso apto para la explotación turística. Básicamente, la tendencia de la demanda marcó que los que fueron nuevos productos ofertados se encontrasen encuadrados en dos grandes paquetes vinculados: medio ambiente físico (la naturaleza) y medio ambiente cultural (patrimonial-identitario) [...] más importante aún fue potenciar el desarrollo del turismo en muchas áreas a las que el clima y la geografía no ayudaron con los turismos clásicos [....]cultura y naturaleza, presentadas a modo de paisajes conjuntos o disociados, segmentados como historia, adaptación monumentalidad, etnografía, fauna, arquitectura, arqueología, flora, gastronomía....así con un orden caótico, han reordenado y definido el sistema”.

2 No son objeto de análisis en nuestro estudio los siguientes bienes naturales y mixtos que también poseen el reconocimiento otorgado por la UNESCO como Patrimonio Mundial: Pirineos-Monte Perdido (provincia de Huesca), declarado en 1997, 1999 (categoría mixta), disponible en: http://www.tuhuesca.com; Ibiza, biodiversidad y cultura (isla Ibiza), declarado en 1999 (categoría mixta), disponible en: http://www.ibiza.travel/es/; Parque Nacional de Garajonay (isla La Gomera), declarado en 1986 (categoría natural), disponible en: http://www.lagomera.travel/; Parque Nacional de Doñana (provincias Huelva y Sevilla), declarado en 1994 (categoría natural), disponible en: http://www.turismohuelva.org/; Parque Nacional del Teide (isla Tenerife), declarado en 2007 (categoría natural), disponible en: http://www.webtenerife.com/

3 La musealización de las ciudades fuerza su identidad hacia la imagen que se ha generado de ellas, incentivando actividades y propuestas que son beneficiosas para el sector turístico. Con este posicionamiento se intenta conservar la ciudad de forma inalterable al paso del tiempo impidiendo una evolución adaptada a sus necesidades como territorio y proporcionando al turista un conocimiento muy básico y puntual de la ciudad.

4 La gentrificación se produce cuando las intervenciones urbanísticas transforman un barrio o un distrito de la ciudad y elevan su estatus socioeconómico. En ocasiones, tales mejoras urbanas hacen que los centros históricos se revaloricen y la población original desaparece para ser sustituida por nuevos ocupantes con mayor poder adquisitivo. Se transmite a la población que gracias a estas intervenciones urbanas se va a mejorar su calidad de vida, cuando lo que se está produciendo realmente es una mera operación especulativa y elitista.

* Este trabajo ha sido desarrollado en el marco del Programa de Redes-I3CE de investigación en docencia universitaria del Instituto de Ciencias de la Educación y el Vicerrectorado de Calidad e Innovación Educativa de la Universidad de Alicante (convocatoria 2018-19). Ref.: (4338) PRORO-COL, Red interuniversitaria de trabajo colaborativo en protocolo, gestión de eventos y RR. institucionales (2010-2019) 